\title{
Ni-Al Alloys as Alternative EUV Mask Absorber
}

\author{
Vu Luong ${ }^{1,2, *}$ (D), Vicky Philipsen ${ }^{1}$, Eric Hendrickx ${ }^{1}$, Karl Opsomer ${ }^{1}$, Christophe Detavernier ${ }^{3}$, \\ Christian Laubis ${ }^{4}$, Frank Scholze ${ }^{4}$ and Marc Heyns ${ }^{1,2}$ \\ 1 IMEC, Kapeldreef 75, B-3001 Leuven, Belgium; vicky.philipsen@imec.be (V.P.); \\ eric.hendrickx@imec.be (E.H.); karl.opsomer@imec.be (K.O.); marc.heyns@imec.be (M.H.) \\ 2 KU Leuven, Department of Materials Engineering, B-3001 Leuven, Belgium \\ 3 Department of Solid-state Sciences, Ghent University, Krijgslaan 281 (S1), B-9000 Gent, Belgium; \\ christophe.detavernier@ugent.be \\ 4 PTB, Abbestraße 2-12, 10587 Berlin, Germany; christian.laubis@ptb.de (C.L.); frank.scholze@ptb.de (F.S.) \\ * Correspondence: vu.luong@imec.be; Tel.: +32-16-28-83-54
}

Received: 31 January 2018; Accepted: 25 March 2018; Published: 29 March 2018

\begin{abstract}
Extreme ultraviolet (EUV) lithography is being industrialized as the next candidate printing technique for high-volume manufacturing of scaled down integrated circuits. At mask level, the combination of EUV light at oblique incidence, absorber thickness, and non-uniform mirror reflectance through incidence angle, creates photomask-induced imaging aberrations, known as mask 3D (M3D) effects. A possible mitigation for the M3D effects in the EUV binary intensity mask (BIM), is to use mask absorber materials with high extinction coefficient $\kappa$ and refractive coefficient $n$ close to unity. We propose nickel aluminide alloys as a candidate BIM absorber material, and characterize them versus a set of specifications that a novel EUV mask absorber must meet. The nickel aluminide samples have reduced crystallinity as compared to metallic nickel, and form a passivating surface oxide layer in neutral solutions. Composition and density profile are investigated to estimate the optical constants, which are then validated with EUV reflectometry. An oxidation-induced A1 L2 absorption edge shift is observed, which significantly impacts the value of $n$ at $13.5 \mathrm{~nm}$ wavelength and moves it closer to unity. The measured optical constants are incorporated in an accurate mask model for rigorous simulations. The M3D imaging impact of the nickel aluminide alloy mask absorbers, which predict significant M3D reduction in comparison to reference absorber materials. In this paper, we present an extensive experimental methodology flow to evaluate candidate mask absorber materials.
\end{abstract}

Keywords: mask absorber; binary intensity mask; nickel; aluminum; mask 3D; imaging impact; EUV lithography

\section{Introduction}

Extreme ultraviolet lithography is being industrialized as the next candidate printing technique for high-volume manufacturing of scaled down microcircuit devices for logic and memory applications. Because of the short wavelength of $13.5 \mathrm{~nm}$ used in extreme ultraviolet (EUV) lithography, it is not possible to use refractive optics or transmission masks for image formation, and the optical elements and EUV photomask are reflective mirrors. The EUV mask is a reflective multilayer (ML) mirror, consisting of molybdenum/silicon (Mo/Si) bilayers having peak reflectivity at $13.5 \mathrm{~nm}$, and is coated with a mask absorber where light has to be attenuated. The chief-ray incidence angle on mask is set at $6^{\circ}$ from normal to avoid overlap of incident and reflected light.

Figure 1 depicts the cross-section of an EUV photomask. The substrate consists of a low thermal expansion material (LTEM) glass plate with a Mo/Si ML mirror coating on front side, and a conductive backside coating for electrostatic chucking. A thin ruthenium $(\mathrm{Ru})$ capping layer protects the mirror 
against oxidation of the top Si layer, and against the cleaning of organic contaminants by hydrogen reduction [1]. Currently, tantalum (Ta) is the main component of most common absorber materials developed for commercial EUV photomasks. The absorber layer is etched into a pattern to be printed on wafer, and is capped with an oxide anti-reflective coating (ARC) to create contrast between the absorber and the mirror for defect inspection in the deep ultraviolet wavelength range (DUV).

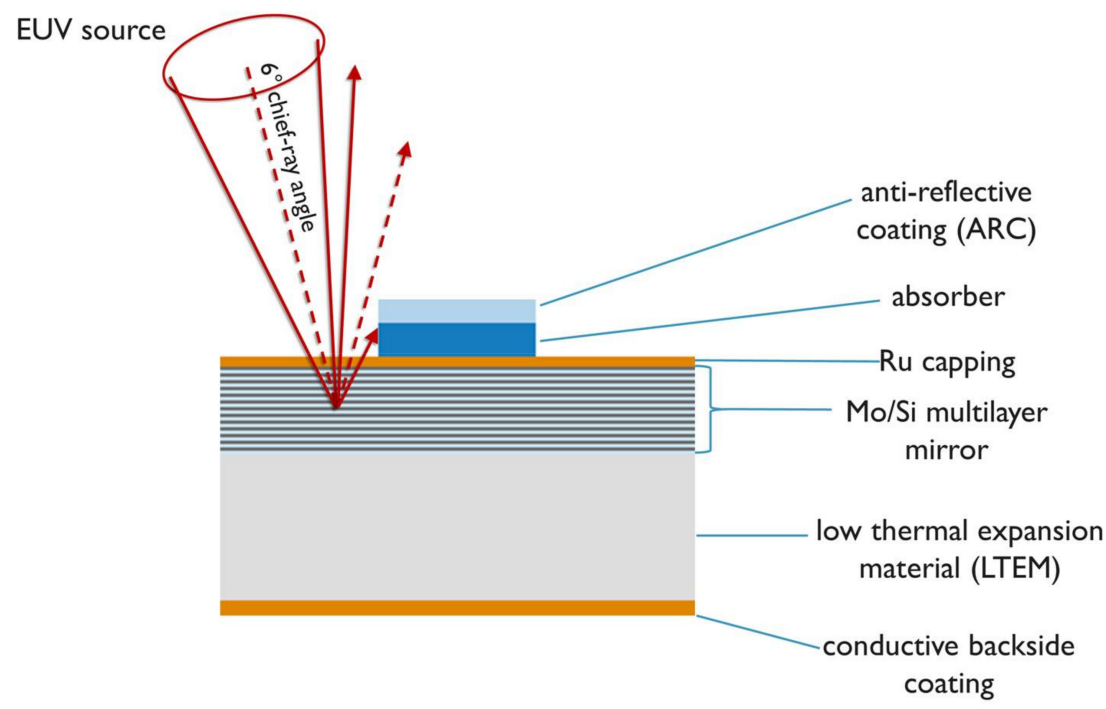

Figure 1. Cross-section of an extreme ultraviolet (EUV) binary intensity mask (BIM). The oblique incident EUV light, with chief ray angle of $6^{\circ}$ from normal, is reflected by the multilayer (ML) mirror or absorbed by the absorber layer. The mask topography has an impact on EUV reflection, resulting in mask 3D (M3D) effects. Angles and thickness are for illustrative purposes only, and are not to scale.

The combination of EUV light at oblique incidence, absorber thickness, and non-uniform mirror reflectance through incidence angle, creates photomask-induced imaging aberrations, known as mask 3D (M3D) effects [2]. These effects are experimentally observable, as feature orientation-dependent shadowing effects [3], best focus variation through pitch [4], feature size-dependent pattern shift through focus [5,6], and pattern asymmetry and contrast loss [7]. Selecting the correct mask absorber material and thickness helps in reducing M3D effects [2,8,9]. This approach is complementary to other M3D mitigation strategies, such as source optimization [10], sub-resolution assist feature placement [11], and transition to anamorphic high-NA EUV lithography [12].

This paper will focus on absorber material as a mitigation strategy for M3D effects, and we verify whether mask absorber materials with high extinction coefficient $\kappa$ and refractive coefficient $n$ close to unity can be generated by combining $\mathrm{Al}$ and $\mathrm{Ni}$ in an alloy. The motivation for this particular material selection is explained in the next section.

In Section 2, we review the material selection criteria, and methods to deposit and characterize the alloys. In Section 3 we elaborate on the film characterization results, such as film morphology and material durability. Composition and density profile are determined to calculate the optical constants, which will be experimentally verified with EUV reflectometry (EUVR). The comparison between the calculated and measured optical constants will be discussed in Section 4. In Section 5, the measured optical constants are incorporated in an accurate mask model for rigorous imaging simulations to determine M3D imaging impact. Finally, we summarize our findings and give an outlook in Section 6.

\section{Materials and Methods}

Novel EUV absorber materials are primarily chosen for their optical performance in the EUV wavelength range, which is described by the complex refractive index. The imaginary part $\kappa$ 
or extinction coefficient determines the attenuation, while the real part $n$ or refraction coefficient determines the phase velocity. To reduce mask absorber height-dependent M3D effects, a material that absorbs more EUV and has higher $\kappa$ than Ta is necessary [2]. Best focus shifts through pitch are caused by phase distortion due to a mismatch in refraction coefficient $n$ at the vacuum and absorber interface, hence a material with $n$ close to unity is preferred [13]. In this paper, the focus will be on material selection for BIM, i.e., high $\kappa$ and $n$ close to unity.

Figure 2 shows the relationship between $n$ and $\kappa$ at $13.5 \mathrm{~nm}$ EUV wavelength of elements from $Z=11$ to $Z=83$, excluding elements from the lanthanide series and noble gases [14]. Nickel (Ni) is one of the highest EUV absorbing elements, but it can easily form crystal grains $[8,9,15]$. Alloying is an option to reduce Ni crystallinity [16]. Aluminum (Al) has non-negligible EUV absorption and $n$ larger than unity. Based on rigorous imaging simulations, $\mathrm{Al}$ is expected to reduce M3D effects $[17,18]$, but imaging contrast will deteriorate due to $\mathrm{Al}^{\prime}$ s lower $\kappa$ compared to Ta. By combining both elements into a $\mathrm{Ni}_{\mathrm{x}} \mathrm{Al}_{\mathrm{y}}$ alloy, we target a material that reduces EUV phase distortion, while maintaining good contrast for imaging at reduced absorber thickness.

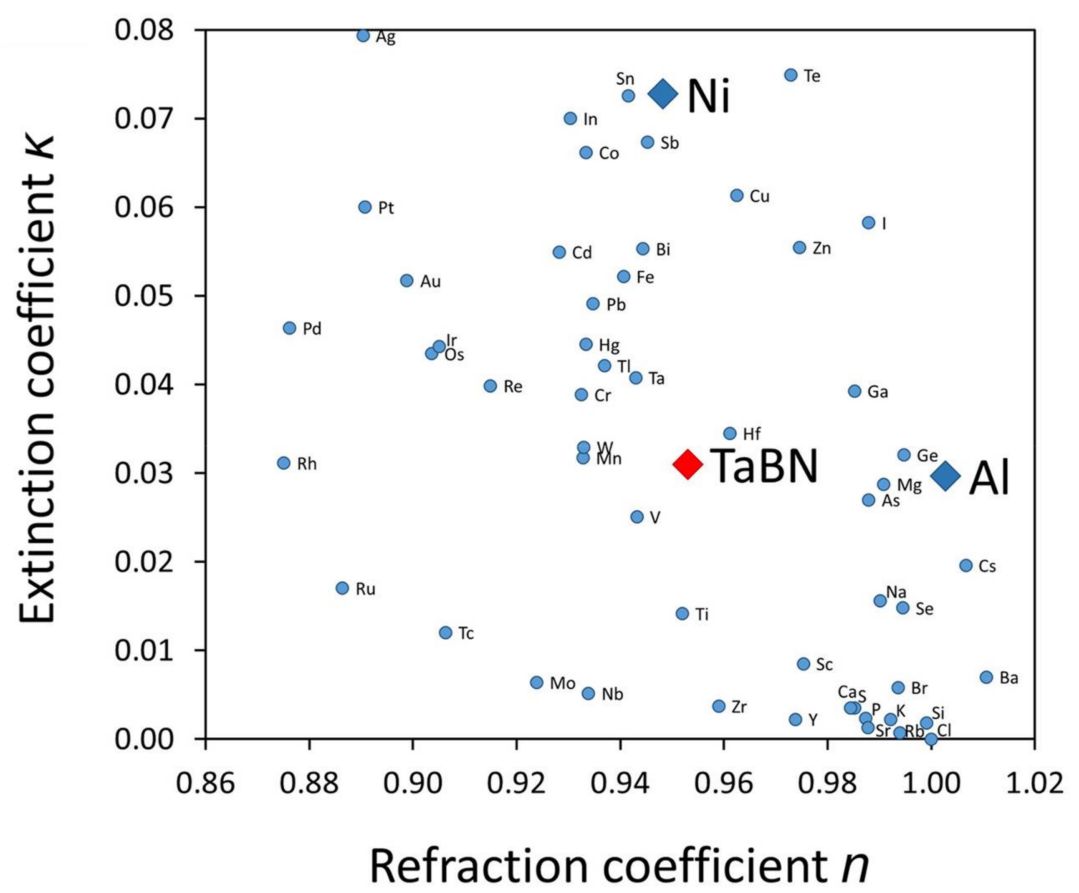

Figure 2. Extinction coefficient $\kappa$ versus refraction coefficient $n$ at $13.5 \mathrm{~nm}$ EUV wavelength for elements with atomic number from $\mathrm{Z}=11(\mathrm{Na})$ to $\mathrm{Z}=83(\mathrm{Bi})$, excluding the lanthanide series and noble gases. Data from Henke et al. [14].

Based on the thermodynamic phase diagram of Ni-Al system in Figure 3 [19], three stable Ni-Al compositions were investigated: $\mathrm{Ni}_{3} \mathrm{Al}, \mathrm{NiAl}$ and $\mathrm{Ni}_{2} \mathrm{Al}_{3}$. The films were deposited with a nominal film thickness of $25 \mathrm{~nm}$ by physical vapor deposition (PVD) through co-depositing $\mathrm{Ni}$ and $\mathrm{Al}$ targets. We used 6" Si-wafer substrates on which $30 \mathrm{~nm} \mathrm{SiO}_{2}$ was grown through wet oxidation. The wafers were mounted on a rotating wafer drum, sequentially passing Ni and Al direct current (DC) plasma's at Ar pressures of $5.10^{-3}$ mbar resulting in alternating $\mathrm{Ni}$ and $\mathrm{Al}$ monolayers deposited and instantaneous intermixing. Furthermore, when selecting new EUV absorber materials, they need to satisfy a set of specifications summarized in Table $1[8,17]$. We present detailed results of the characterization with respect to some of these properties. Determining the optical constants of the absorber material with EUV reflectance requires an accurate absorber stack model, for which additional metrology is needed to assess the chemical composition and density profile of the absorber film. 


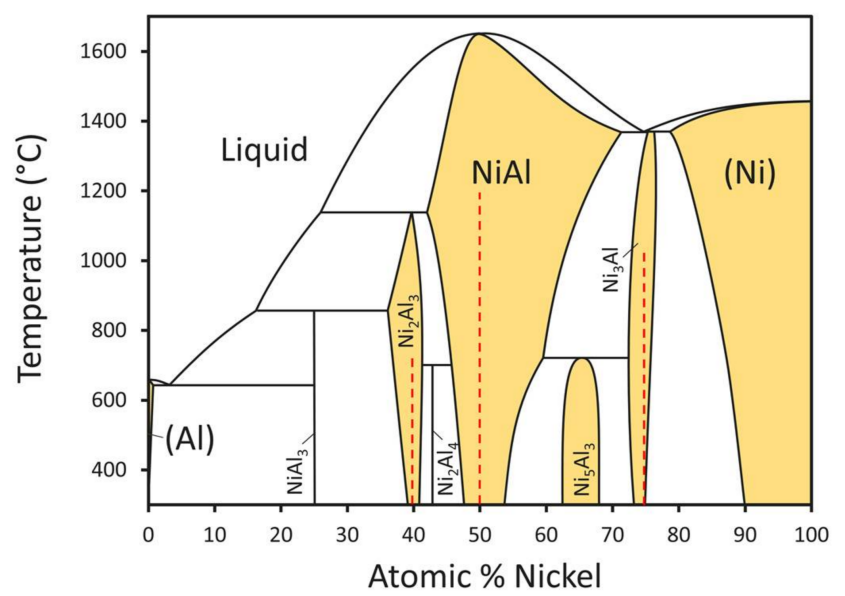

Figure 3. Thermodynamic binary phase diagram of Ni-Al system. Stable phases are colored yellow. Red dashed lines represent the nominal $\mathrm{Ni}_{\mathrm{x}} \mathrm{Al}_{\mathrm{y}}$ compositions. Reproduced from Saltykov et al. [19].

Table 1. Specifications for novel EUV absorbers and the performed metrology.

\begin{tabular}{|c|c|c|}
\hline Characterization & Specification & Metrology Performed \\
\hline \multirow{3}{*}{ Film morphology } & \multirow[b]{2}{*}{$\begin{array}{l}\text { Amorphous or nano-crystalline to reduce } \\
\text { line edge roughness }[18,19]\end{array}$} & Transmission electron microscopy (TEM) \\
\hline & & $\begin{array}{l}\text { X-ray diffraction (XRD): theta-2theta } \\
\text { configuration to determine crystal orientation } \\
\text { parallel to surface [20]. In-situ XRD (IS-XRD) to } \\
\text { inspect crystallization across temperature range }\end{array}$ \\
\hline & $\begin{array}{l}\text { Reference TaBN absorber has surface } \\
\text { roughness }<0.3 \mathrm{~nm} \text { RMS [21] }\end{array}$ & - \\
\hline Mechanical stress & $\begin{array}{l}\text { Residual film stress of full photomask stack } \\
\text { must be within } \pm 180 \mathrm{GPa} \text { to maintain } \\
\text { photomask flatness [21] }\end{array}$ & - \\
\hline \multirow{3}{*}{ Mask processing } & $\begin{array}{l}\text { Good adhesion on Ru capping layer, } \\
\text { including during cleaning }\end{array}$ & - \\
\hline & $\begin{array}{l}\text { Small critical dimension (CD) etch bias and } \\
\text { etch selectivity to the capping layer }\end{array}$ & - \\
\hline & $\begin{array}{l}\text { Thermal budget }<150^{\circ} \mathrm{C} \text { to protect the } \mathrm{ML} \\
\text { mirror's reflectance [22] }\end{array}$ & - \\
\hline \multirow{3}{*}{$\begin{array}{l}\text { Scanner } \\
\text { compatibility }\end{array}$} & $\begin{array}{l}\text { Low vapor pressure to avoid volatile } \\
\text { formation at reduced scanner pressure, in } \\
\text { combination with elevated temperature } \\
\text { during exposure [23] }\end{array}$ & - \\
\hline & $\begin{array}{l}\text { No phase transformation between room } \\
\text { temperature and working temperature }\end{array}$ & - \\
\hline & Hydrogen resistant & $\begin{array}{l}110 \mathrm{~h} \text { of exposure to } \mathrm{H}^{*} \text { radicals, generated by } \\
\text { EUV Tech hydrogen cleaner [24]; } \\
\text { Composition change measured with Rutherford } \\
\text { backscattering spectroscopy (RBS) and elastic } \\
\text { recoil detection analysis (ERDA) }\end{array}$ \\
\hline Defect inspection & $\begin{array}{l}\text { Oxide anti-reflective coating (ARC) for } \\
\text { contrast in deep ultraviolet wavelength } \\
\text { range (DUV) inspection }\end{array}$ & - \\
\hline Defect repair & $\begin{array}{l}\text { Capability to form volatiles to be } \\
\text { compatible with electron beam repair }\end{array}$ & - \\
\hline Cleaning durability & $\begin{array}{l}\text { Stable in (preferably basic) cleaning } \\
\text { solutions [25] }\end{array}$ & $\begin{array}{l}\text { Beaker test by submerging alloys in solutions of } \\
\text { deionized water (DIW) and ammonium } \\
\text { hydroxide } \mathrm{NH}_{4} \mathrm{OH} \text {; } \\
\text { Composition change measured with RBS/ERDA }\end{array}$ \\
\hline Optical constants & High $\kappa$ and $n$ close to unity & EUVR for fitting optical constants $[20,26]$ \\
\hline
\end{tabular}


The absorber film morphology is preferably nano-crystalline or amorphous, which is challenging to achieve for most single metals. Crystallinity however, is very likely to impair surface roughness and etch bias. Preferential etching along crystal grains can cause increased absorber line edge roughness (LER) and lead to critical dimension (CD) variations, which will be transferred to wafer $[27,28]$. Additionally, absorber morphology affects mechanical film stress. Stress induced by absorber, and ML mirror must be controlled within a range of $\pm 180 \mathrm{GPa}$ to ensure the flatness of the photomask [19] and to avoid distortion-induced pattern placement error [29]. Doping or alloying with additional elements, or a multilayered absorber structure are possible solutions to reduce crystallinity $[15,30]$. We have measured alloy crystallinity using X-ray diffractometry (XRD) and transmission electron microscopy (TEM).

During processing, temperature must be below $150{ }^{\circ} \mathrm{C}$ to avoid intermixing between the mirror's Mo/Si bilayers to maintain high EUV reflectance [22]. This constraint limits deposition of the absorber film to PVD, as most chemical deposition techniques require high temperature [31]. The low temperature during PVD, causes the material deposition to be mainly kinetically controlled. Most atoms will lack the energy to arrange themselves into the most efficient close-packed lattice. Hence the crystal density as reported for the thermodynamically stable crystalline compound will likely not be obtained.

Anisotropic etch of the absorber material must be capable of forming well defined patterns with straight sidewalls. Reactive ion etch (RIE) ensures these conditions, but requires the absorber material to chemically react with the etchant gas and to form volatile compounds below $150^{\circ} \mathrm{C}$. Materials with small CD difference before and after etch are preferred [32,33]. Furthermore, the absorber material must have good adhesion to the Ru capping layer, even during cleaning, and with good etch selectivity to Ru.

Etch development of alternative metals is an important challenge to solve. Despite good imaging performance and durability, Ni remains difficult to pattern. Physical sputtering has limited etch selectivity and cannot obtain the required pattern quality, due to uncontrolled redeposition of non-volatile Ni particles, resulting in sloped sidewalls and Ni residues on the mirror [9]. However, $\mathrm{Ni}$ can form volatile organo-metallic compounds at low temperature [34,35], and emerging etch technology, such as atomic layer etch (ALE), can be promising for enabling transitional metal plasma etch [36]. Alternatively, a damascene-like additive patterning scheme can be adopted to circumvent the direct Ni etching [37]. This solution requires the ability to remove the template pattern selectively afterwards. Furthermore, the ability to form volatile Ni compounds induced by electron beam is still necessary for absorber defect repair of such Ni patterns.

The absorber must remain inert in the EUV scanner ambient, and at the elevated temperatures during EUV exposure. It is not allowed to transform into a different solid phase to avoid volumetric changes. A phase transition of $\mathrm{Ni}_{\mathrm{x}} \mathrm{Al}_{\mathrm{y}}$ alloy is unlikely below $150{ }^{\circ} \mathrm{C}$ though (cf. Figure 3), as both elemental $\mathrm{Ni}$ and $\mathrm{Al}$ have melting points much higher than the thermal budget for EUV photomasks. $\mathrm{H}_{2}$ is used inside the projection optics (PO) box in EUV scanners [38]. Although the photomask is physically outside of the PO box, concerns remain on their capability to react with hydrogen under EUV exposure. A first estimation for the hydrogen durability of an element, is by assessing the volatility or melting point of its hydrogen compound. This assessment however, does not give information on kinetics or ease of formation of such compounds under scanner conditions. Hydrogen resistance can be additionally improved by doping with reduction resistant elements [39]. We have tested hydrogen compatibility by exposing the alloy samples to $\mathrm{H}^{*}$ radicals for $110 \mathrm{~h}$. Composition changes after the durability tests were measured with RBS for Ni detection and elastic recoil detection analysis (ERDA) for $\mathrm{Al}$ detection.

For mask defect inspection in the DUV wavelength range, an oxide ARC is required to create contrast with the mirror where the absorber material has been etched away. For actinic inspection, the ARC layer is not necessary [40]. Another function of the ARC layer is to limit the native oxide growth of the absorber material. For defect repair the absorber material must be able to form volatile compounds by electron beam-induced chemical reaction [41]. Alternatively, nanomachining repair can remove 
non-volatile materials, but is less selective [42]. The absorber must remain stable under cleaning conditions, preferably basic solution to prevent the Ru capping layer from oxidizing and peeling [25]. The introduction of pellicles in EUV lithography will likely reduce the number of cleaning cycles necessary during the lifetime of an EUV mask. In this paper, we have tested cleaning compatibility of $\mathrm{Ni}_{\mathrm{x}} \mathrm{Al}_{\mathrm{y}}$ alloy samples by $24 \mathrm{~h}$ submersion tests in DIW, and in $\mathrm{NH}_{4} \mathrm{OH}$.

Finally, the optical constants are determined through calculation with Equation (1), and through experimental verification with EUVR. Equation (1) relates the optical constants to the semi-empirically determined atomic scattering factors through wavelength as follows:

$$
n(\lambda)=n(\lambda)-i \kappa(\lambda)=1-\frac{r_{0}}{2 \pi} \lambda^{2} N_{A} \sum_{j} \frac{w_{j}}{M_{j}} \rho_{\text {alloy }}\left[f_{1, j}(\lambda)-i f_{2, j}(\lambda)\right]
$$

with $r_{0}$ the classical electron radius, $\lambda$ the wavelength, $N_{A}$ Avogadro constant, $\rho_{\text {alloy }}$ the alloy density, $w_{j}$ and $M_{j}$ the weight percentage and molar mass of the $j$ th element respectively, $f_{1, j}$ and $f_{2, j}$ the real and imaginary part of the forward atomic scattering factor of the $j$ th element respectively, tabulated by Henke et al. [14]. To use Equation (1), one needs to know first the elemental composition, through $w_{j}$, and density $\rho_{\text {alloy, }}$ which are characterized by X-ray photoelectron spectroscopy (XPS), X-ray reflectometry (XRR) and TEM with energy dispersive X-ray analysis (TEM-EDS), as tabulated in Table 2.

Table 2. Methods for thin film composition and density determination.

\begin{tabular}{cc}
\hline Characterization & Metrology \\
\hline Surface chemical state & X-ray photoelectron spectroscopy (XPS) [26] \\
\hline Bulk elemental composition & $\begin{array}{c}\text { Sputter-assisted XPS for composition depth profile } \\
\text { TEM with energy dispersive X-ray analysis (TEM-EDS) }\end{array}$ \\
\hline Density for optical constant estimation & X-ray reflectometry (XRR) \\
\hline Layer thickness & XRR and TEM \\
\hline
\end{tabular}

In the second method, the optical constants are fitted from EUVR measurement through wavelength and through incidence angle. An accurate stack model as a starting point, with correct number of layers and layer thicknesses, can improve fitting convergence towards a set of optical constants. Such a stack model has been verified with XRR and TEM.

\section{Film Characterization}

In this section, we present and elaborate on the film characterization results. We investigated film morphology, material durability, composition and density profile, using metrology as defined in Tables 1 and 2. Composition and density profile results will be used to setup models for extracting optical constants in Section 4.

\subsection{Film Morphology}

The degree of crystallinity of the as-deposited film provides an estimation for the susceptibility to surface roughness and LER. The absorber morphology is preferably nano-crystalline or amorphous, and can be determined using cross sectional TEM and XRD.

Figure 4 a displays the cross-section TEM images of $\mathrm{Ni}_{3} \mathrm{Al}, \mathrm{NiAl}$ and $\mathrm{Ni}_{2} \mathrm{Al}_{3}$. An amorphous native oxide layer is clearly visible on the sample surface, which grows thicker with increasing Al-ratio. All $\mathrm{Ni}_{\mathrm{x}} \mathrm{Al}_{\mathrm{y}}$ compositions are polycrystalline, which can be observed as contrast and lattice orientation change in the Moiré patterns.

Figure $4 \mathrm{~b}$ presents the same samples under different magnification and contrast to better visualize the crystal grains. $\mathrm{Ni}_{3} \mathrm{Al}$ and $\mathrm{NiAl}$ have similar crystallinity with columnar grains spanning the full film thickness. $\mathrm{Ni}_{2} \mathrm{Al}_{3}$ exhibits smaller grains near the surface and substrate interface. 


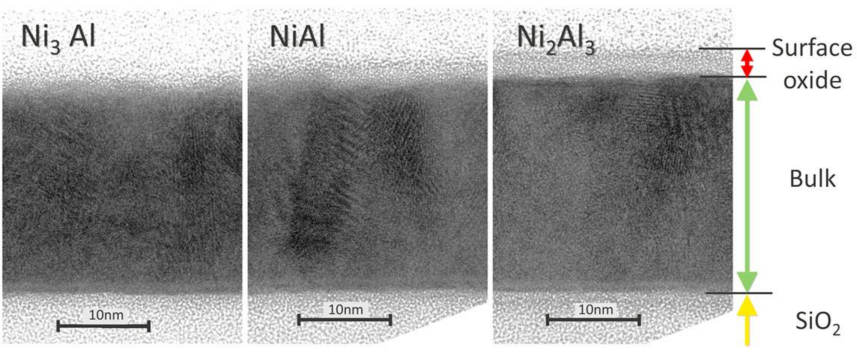

(a)

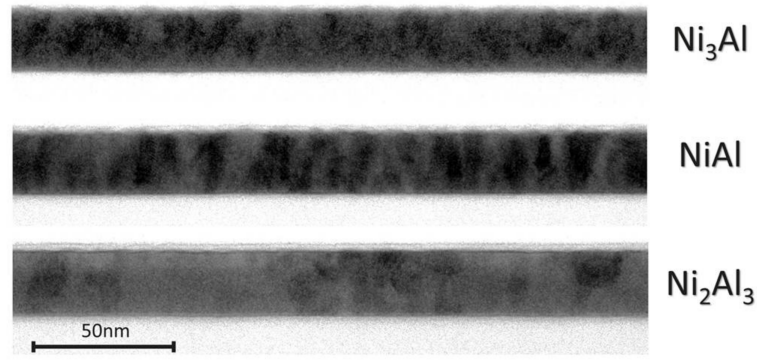

(b)

Figure 4. (a) TEM images of $\mathrm{Ni}_{3} \mathrm{Al}, \mathrm{NiAl}$ and $\mathrm{Ni}_{2} \mathrm{Al}_{3}$ film cross-section; (b) Comparison crystallinity of $\mathrm{Ni}_{3} \mathrm{Al}, \mathrm{NiAl}$ and $\mathrm{Ni}_{2} \mathrm{Al}_{3}$.

Crystallinity is further investigated with XRD scans in Bragg-Brentano geometry, which is mostly sensitive to lattice planes parallel to the film surface. The atomic planes of a crystal cause incidence X-rays to diffract in specific angles. The most intense diffraction peak of a reference Ni film of $25 \mathrm{~nm}$ is located at $44^{\circ} 2$ theta, which is caused by $\mathrm{Ni}(111)$ oriented lattice planes. The full width at half-maximum (FWHM) of the Ni (111) peak can be used to estimate the average crystal grain size $\tau$ through the Scherrer's equation [43], with $K$ the crystal shape-dependent Scherrer constant, $\lambda$ the $C u$ $\mathrm{K} \alpha \mathrm{X}$-ray wavelength, and $\theta$ the X-ray incident angle corresponding to the observed XRD peak:

$$
\tau=\frac{\mathrm{K} \lambda}{\mathrm{FWHM} \cos (\theta)}
$$

The XRD spectra of $\mathrm{Ni}_{x} \mathrm{Al}_{\mathrm{y}}$ films are compared with a reference $25 \mathrm{~nm}$ thick $\mathrm{Ni}$ film, and are monitored with in-situ XRD (IS-XRD) during thermal loading up to $500{ }^{\circ} \mathrm{C}$. After cooling down to room temperature, the XRD spectra of the $\mathrm{Ni}_{\mathrm{x}} \mathrm{Al}_{\mathrm{y}}$ films are measured again.

Figure 5a compares the XRD spectra of the as-deposited films, and of the films after thermal loading. Peak fitting results and estimated average grain size are tabulated in Table 3.

Table 3. Peak position, full width at half-maximum (FWHM) and estimated average $\mathrm{Ni}(-\mathrm{Al})$ grain size of $\mathrm{Ni}, \mathrm{Ni}_{3} \mathrm{Al}, \mathrm{NiAl}$, and $\mathrm{Ni}_{2} \mathrm{Al}_{3}$ as-deposited and after thermal loading up to $500{ }^{\circ} \mathrm{C}$ by in-situ X-ray diffractometry (IS-XRD).

\begin{tabular}{|c|c|c|c|c|}
\hline Sample & $\begin{array}{l}\text { Before/After Thermal } \\
\text { Loading to } 500{ }^{\circ} \mathrm{C}\end{array}$ & $\begin{array}{l}\text { Peak Position } \\
2 \theta\left({ }^{\circ}\right)\end{array}$ & FWHM $\left(^{\circ}\right)$ & $\begin{array}{c}\text { Avg. Ni(-Al) } \\
\text { Grain Size } \tau(\mathrm{nm})\end{array}$ \\
\hline $\mathrm{Ni}$ & before & $44.430 \pm 0.011$ & $0.653 \pm 0.035$ & $13.7 \pm 5.4 \%$ \\
\hline $\mathrm{Ni}_{3} \mathrm{Al}$ & $\begin{array}{l}\text { before } \\
\text { after }\end{array}$ & $\begin{array}{l}44.607 \pm 0.013 \\
44.457 \pm 0.009\end{array}$ & $\begin{array}{l}1.894 \pm 0.052 \\
1.851 \pm 0.034\end{array}$ & $\begin{array}{l}4.7 \pm 2.7 \% \\
4.8 \pm 2.0 \%\end{array}$ \\
\hline NiAl & $\begin{array}{l}\text { before } \\
\text { after }\end{array}$ & $\begin{array}{l}44.618 \pm 0.006 \\
44.688 \pm 0.004\end{array}$ & $\begin{array}{l}0.794 \pm 0.018 \\
0.676 \pm 0.011\end{array}$ & $\begin{array}{l}11.3 \pm 2.2 \% \\
13.3 \pm 1.7 \%\end{array}$ \\
\hline $\mathrm{Ni}_{2} \mathrm{Al}_{3}$ & $\begin{array}{c}\text { before } \\
\text { after }\end{array}$ & $\begin{array}{l}44.502 \pm 0.044 \\
45.239 \pm 0.007\end{array}$ & $\begin{array}{l}1.323 \pm 0.157 \\
0.687 \pm 0.021\end{array}$ & $\begin{array}{c}6.8 \pm 12 \% \\
13.1 \pm 3.1 \%\end{array}$ \\
\hline
\end{tabular}




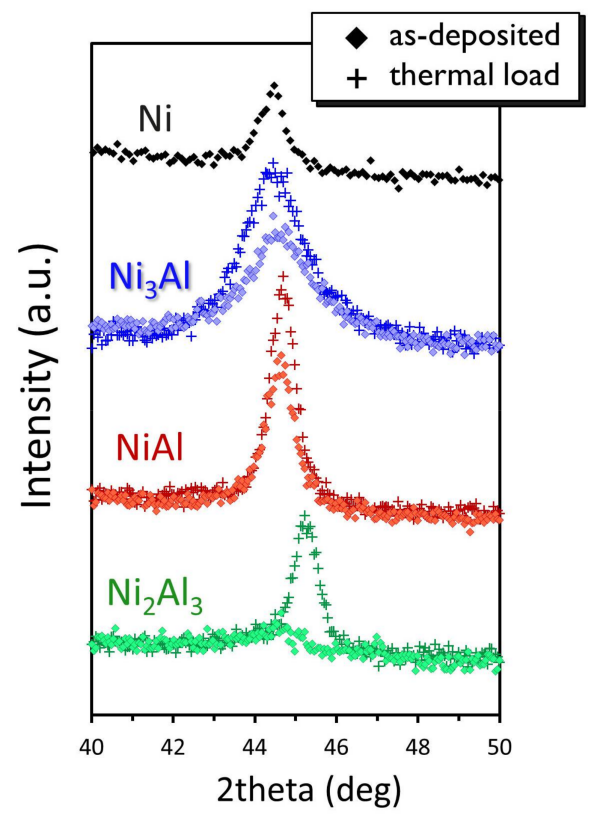

(a)
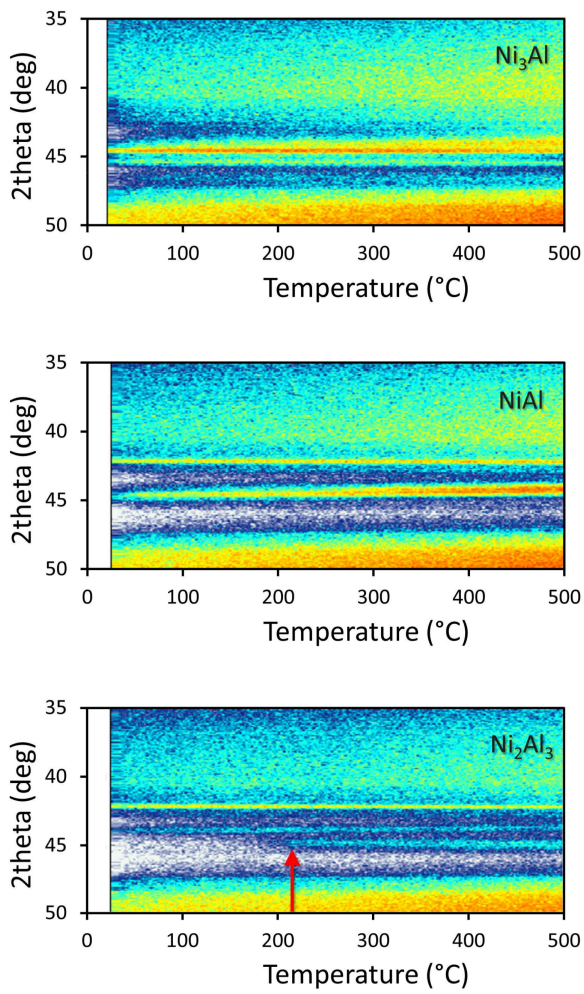

(b)

Figure 5. (a) X-ray diffractometry (XRD) spectra of $\mathrm{Ni}$ (black), $\mathrm{Ni}_{3} \mathrm{Al}$ (blue), $\mathrm{NiAl}$ (red), and $\mathrm{Ni}_{2} \mathrm{Al}_{3}$ (green). Samples as-deposited and after thermal load up to $500{ }^{\circ} \mathrm{C}$, are represented by diamonds and plus signs respectively; (b) In-situ XRD (IS-XRD) spectra of $\mathrm{Ni}_{3} \mathrm{Al}, \mathrm{NiAl}$, and $\mathrm{Ni}_{2} \mathrm{Al}_{3}$, showing the evolution of diffracted intensity as function of the temperatures of measurement. The intensity scale is represented in a pseudo-color map, with white representing the lowest intensity, blue intermediate intensity and red highest intensity. Onset of $\mathrm{Ni}_{2} \mathrm{Al}_{3}$ recrystallization is indicated by the red arrow.

Compared to the reference $\mathrm{Ni}$ (111) peak, the peak of as-deposited $\mathrm{Ni}_{3} \mathrm{Al}$ appears much broader, indicating smaller $\mathrm{Ni}_{3} \mathrm{Al}$ crystal grains. As-deposited $\mathrm{NiAl}$ exhibit a peak more similar to the reference $\mathrm{Ni}$ film. For as-deposited $\mathrm{Ni}_{2} \mathrm{Al}_{3}$, no clear XRD peaks can be observed, indicating poor condition for diffraction. Possible causes include nano-crystallinity, more variation in average grain size, and random orientation of the crystal lattice. After thermal loading and cooling down to room temperature, the peak position of both $\mathrm{Ni}_{3} \mathrm{Al}$ and $\mathrm{NiAl}$ remains the same, indicating no crystalline phase change occurred. The peak width has decreased slightly, suggesting the crystal grains have grown. The $\mathrm{Ni}_{2} \mathrm{Al}_{3}$ peak however, has shifted and increased significantly in intensity after thermal loading, indicating recrystallization into a different crystalline phase.

Figure $5 \mathrm{~b}$ confirms $\mathrm{Ni}_{2} \mathrm{Al}_{3}$ recrystallization started after $200{ }^{\circ} \mathrm{C}$. Taking the IS-XRD results into consideration, it is unlikely that a mask absorber comprising of only $\mathrm{Ni}$ and $\mathrm{Al}$, will remain amorphous under working conditions. However, we have achieved a reduction in crystal grain size by alloying Ni with $\mathrm{Al}$ under unequal nominal $\mathrm{Ni}$ Al ratio.

\subsection{Durability}

The photomask material must remain stable under cleaning conditions and working scanner conditions during the mask lifetime.

The initial cleaning durability test composes of submerging samples in two solutions with different acidity: DIW (slightly acidic pH 5.7 due to $\mathrm{CO}_{2}$ diffusion from atmosphere) and $\mathrm{NH}_{4} \mathrm{OH}$ (basic $\mathrm{pH}$ 11.4). Hydrogen durability was tested by exposing samples to a flow of $\mathrm{H}^{*}$ radicals over 
a period of $110 \mathrm{~h} . \mathrm{H}^{*}$ radicals were formed through cracking $\mathrm{H}_{2}$ with a hot tungsten filament using a EUV Tech hydrogen cleaner [24]. After the durability tests the samples, together with a reference, were measured with XRR and RBS/ERDA to assess thickness and composition changes respectively. The results are depicted in Figure 6a.

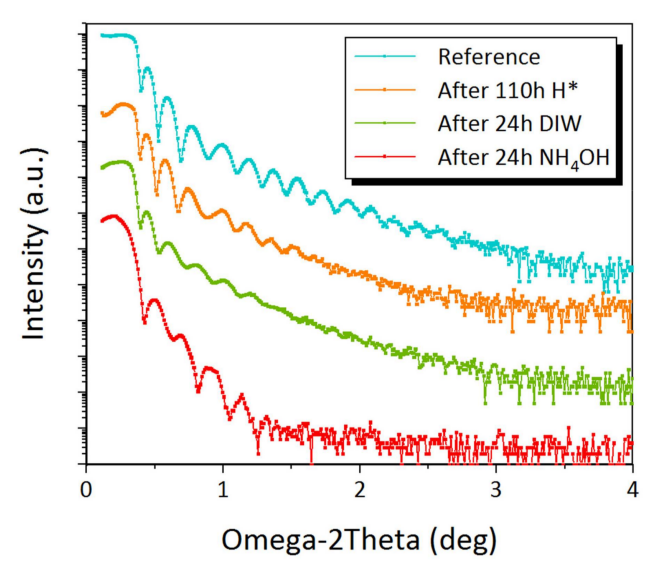

(a)

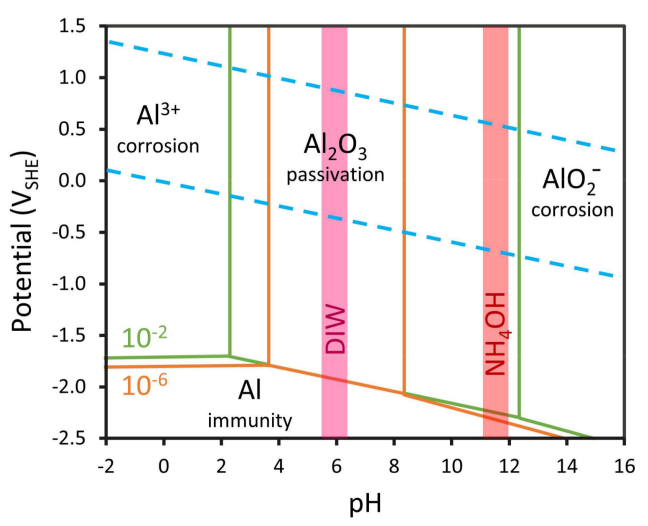

(b)

Figure 6. (a) X-ray reflectometry (XRR) spectra of $\mathrm{Ni}_{3} \mathrm{Al}$ reference, after $110 \mathrm{~h} \mathrm{H}^{*}$, after $24 \mathrm{~h} \mathrm{DIW}$, and after $24 \mathrm{~h} \mathrm{NH} \mathrm{NH}_{4} \mathrm{OH}$ (b) Pourbaix diagram of $\mathrm{Al}$-water system at $25^{\circ} \mathrm{C}$, showing the phases of $\mathrm{Al}$ in function of electrochemical potential $\mathrm{V}_{\mathrm{SHE}}$ and acidity $\mathrm{pH}$, at an effective $\mathrm{Al}^{3+} / \mathrm{AlO}_{2}{ }^{-}$concentration of $10^{-6}$ (orange line) and $10^{-2}$ (green line). The $\mathrm{pH}$ range of $\mathrm{DIW}$, and $\mathrm{NH}_{4} \mathrm{OH}$ are shown in purple, and red respectively. The stability region of water lies between the dashed blue lines. Modified from Pourbaix [44].

The XRR spectra of $\mathrm{Ni}_{3} \mathrm{Al}$ reference and after $110 \mathrm{~h} \mathrm{H}^{*}$ have the same oscillation frequency, indicating no thickness loss. There is a slight increase in roughness after $\mathrm{H}^{*}$ test, which can be recognized as attenuation of the amplitude at higher incident angles. Attenuation is also observed in the samples after $24 \mathrm{~h}$ in DIW, and even more so in $\mathrm{NH}_{4} \mathrm{OH}$. Furthermore, a reduction in oscillation frequency indicates a film thickness loss for the sample in $\mathrm{NH}_{4} \mathrm{OH}$. The Pourbaix diagram shown in Figure $6 b$, helps understanding the behavior of $\mathrm{Al}$ in aqueous solution [44]. The thermodynamic stable phases of $\mathrm{Al}$ are shown in relation to the solution's electrochemical potential $\mathrm{V}_{\mathrm{SHE}}$, acidity $\mathrm{pH}$, and effective concentration of the soluble species $\left(\mathrm{Al}^{3+}\right.$ and $\left.\mathrm{AlO}_{2}{ }^{-}\right)$. The stability region of water lies between the dashed blue lines, which define the reduction and oxidation reaction of water. Under negative $\mathrm{V}_{\mathrm{SHE}}$ or highly reducing condition, metallic $\mathrm{Al}$ is immune to reaction in aqueous solution. Under more oxidizing condition, Al will react depending on the acidity. Highly acidic and highly basic condition will dissolve $\mathrm{Al}$ into soluble $\mathrm{Al}^{3+}$ and $\mathrm{AlO}_{2}{ }^{-}$ions respectively, causing corrosion of the surface Al. Therefore, a thickness loss and increased roughness are observed by XRR for the sample in $\mathrm{NH}_{4} \mathrm{OH}$. Around neutral $\mathrm{pH}, \mathrm{Al}$ reacts by forming an $\mathrm{Al}_{2} \mathrm{O}_{3}$ layer that functions as a stable passivation layer against corrosion. Based on XRR measurement, the passivating $\mathrm{Al}_{2} \mathrm{O}_{3}$ layer causes increased roughness. The $\mathrm{pH}$-range of the passivating region is also dependent on the concentration of $\mathrm{Al}^{3+}$ and $\mathrm{AlO}_{2}{ }^{-}$in the solution. The driving force for $\mathrm{Al}$ dissolution is larger in diluted solutions, resulting in a small passivation region between $\mathrm{pH} 4$ and 8 (orange line). Solutions with high $\mathrm{Al}^{3+} / \mathrm{AlO}_{2}{ }^{-}$ concentration, can increase the passivation region even more towards basic conditions (green line).

The average composition changes of $\mathrm{Ni}_{3} \mathrm{Al}$ are compared between a reference sample, after $110 \mathrm{~h}$ $\mathrm{H}^{*}$, and after $24 \mathrm{~h}$ DIW. The basic cleaning condition with $\mathrm{NH}_{4} \mathrm{OH}$ was disregarded, as $\mathrm{Al}$ was not stable under this condition. Ion beam characterization techniques, such as RBS and ERDA, are very sensitive to changes in elemental composition. These techniques were used to measure $\mathrm{Ni}$ and $\mathrm{Al}$ areal atomic density. As Ni was expected to be stable under the conditions of the durability tests $[13,45]$, the 
$\mathrm{Ni}$ areal atomic density was used for normalization. The relative atomic density of $\mathrm{Ni}, \mathrm{Al}, \mathrm{O}, \mathrm{C}$ and $\mathrm{H}$, are presented in Figure 7.
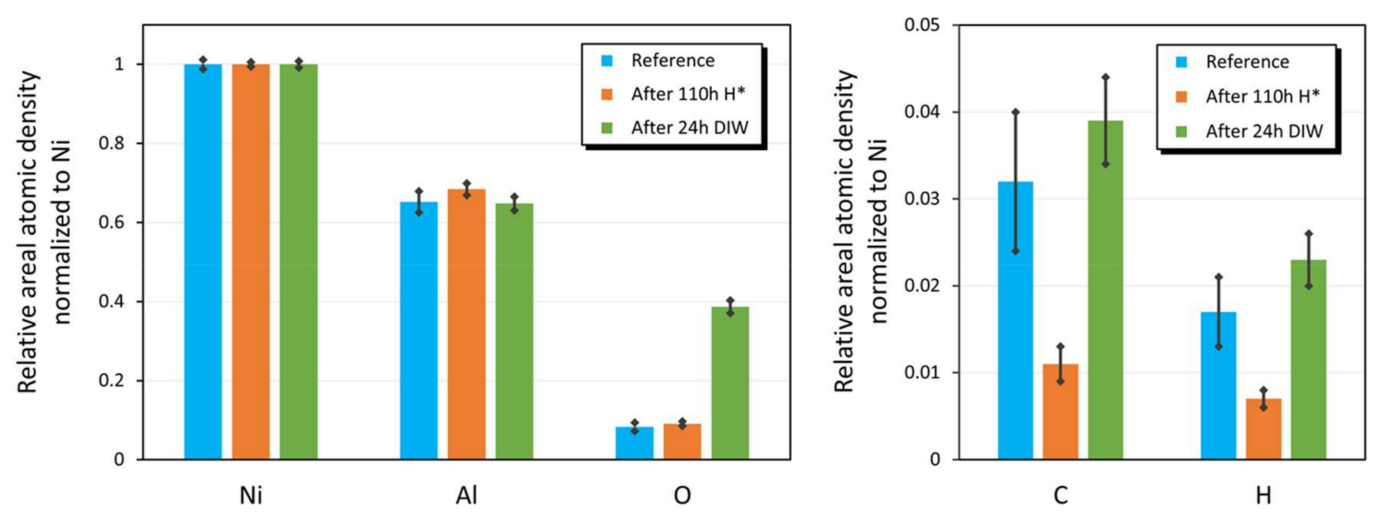

Figure 7. Average composition comparison of $\mathrm{Ni}_{3} \mathrm{Al}$ reference, after $110 \mathrm{~h} \mathrm{H}^{*}$, and after $24 \mathrm{~h} \mathrm{DIW.}$ The areal atomic density is normalized to Ni signal. The error bars represent the areal atomic density standard deviation.

The Ni:Al ratio remained around 3:2. Though, a significant increase in oxygen content is observed after $24 \mathrm{~h}$ in DIW, which is consistent with the Pourbaix diagram. Likely, more O-bonds has been formed, resulting in increased roughness, yet without changing the total thickness as the XRR oscillation frequency did not increase. Furthermore, traces of $\mathrm{C}$ and $\mathrm{H}$ are clearly reduced after $\mathrm{H}^{*}$ exposure, which is not unexpected as $\mathrm{H}^{*}$ is used in mask cleaning processes to reduce organic contamination. Note that traces of $\mathrm{C}$ and $\mathrm{H}$ have not been reduced after DIW cleaning procedure.

We have conducted durability tests on $\mathrm{Ni}_{3} \mathrm{Al}$. The behavior of $\mathrm{NiAl}$ and $\mathrm{Ni}_{2} \mathrm{Al}_{3}$ are expected to be like $\mathrm{Ni}_{3} \mathrm{Al}$, as all three samples exhibit the same native oxide. The surface $\mathrm{Al}$ oxide dissolves in $\mathrm{NH}_{4} \mathrm{OH}$, but remains stable in DIW, though metallic $\mathrm{Al}$ will be further oxidized and might increase roughness. The Ni:Al ratio remained the same after DIW submersion and after $\mathrm{H}^{*}$ tests, indicating neither preferential dissolution nor preferential sputtering has occurred respectively. To be compatible with more basic conditions, a cleaning solution with high $\mathrm{Al}^{3+} / \mathrm{AlO}_{2}{ }^{-}$concentration can increase the passivation region. Alternatively, a capping layer can limit the exposure of the surface $\mathrm{Al}$ to the surroundings, thereby limiting oxidation. Another option is to saturate all Al-O bonds during deposition, while aiming for low surface roughness. This way, the roughness remains low as no further oxidation will occur during cleaning under passivation conditions.

\subsection{Composition and Density Profile}

The composition and density of the absorber material is needed to estimate its theoretical optical constants by providing the weight percentage $w_{j}$ and alloy density $\rho_{\text {alloy }}$ in Equation (1) respectively. Many metals form a native surface oxide layer as well, which will be determined with XPS and TEM-EDS. The composition and density of both surface oxide and bulk layer can be determined by fitting XRR measurements.

XPS is an effective technique to determine the oxidation state on the surface, which provides information on whether the atom is bound in a compound, or whether it is in pure metallic state. Depth profile can be obtained in sputter-assisted mode. XPS measurement of $\mathrm{Ni}_{2} \mathrm{Al}_{3}$ is presented in Figure 8. XPS data for $\mathrm{Ni}_{3} \mathrm{Al}$ and $\mathrm{NiAl}$ are available in the Supplementary Materials section Figure S1.

$\mathrm{Ni} 2 \mathrm{p}_{3 / 2}$, and $\mathrm{Ni} 2 \mathrm{p}_{1 / 2}$ peaks are found at $852.7 \mathrm{eV}$, and $870.0 \mathrm{eV}$ respectively. On the surface, there is a negligible amount of $\mathrm{Ni}$ present. The peak positions inside the bulk of the film correspond to metallic $\mathrm{Ni}$. In case $\mathrm{Ni}$ was in a compound, the $\mathrm{Ni} 2 \mathrm{p}_{3 / 2}$ and $\mathrm{Ni} 2 \mathrm{p}_{1 / 2}$ peaks will shift slightly to higher binding energy around $854.4 \mathrm{eV}$ and $871.9 \mathrm{eV}$ respectively, possibly splitting in multiplet peaks and having more pronounced satellite peaks. 


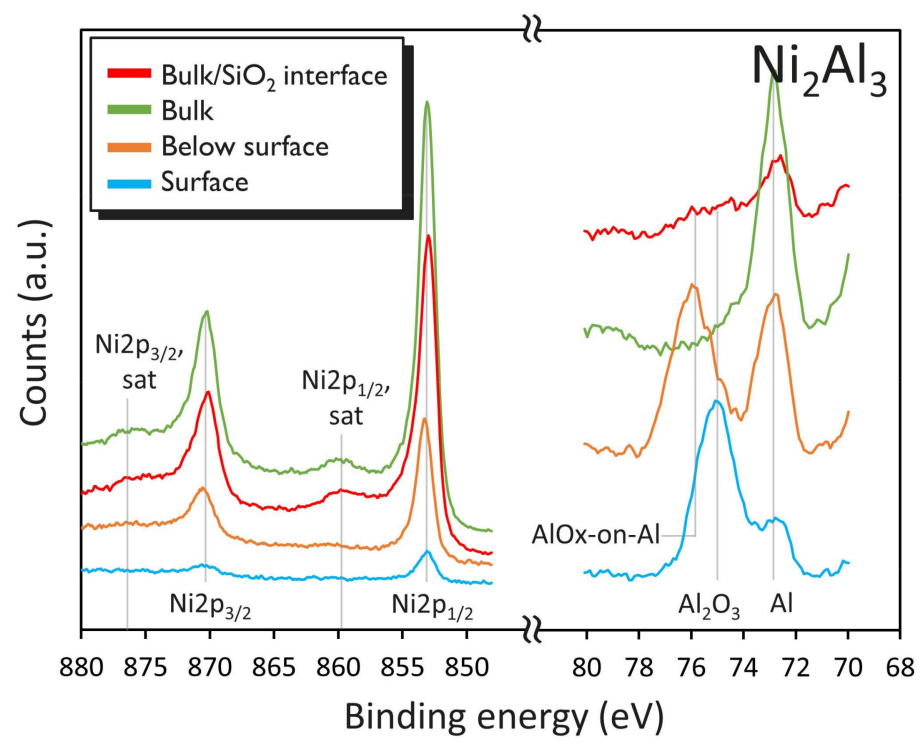

Figure 8. X-ray photoelectron spectroscopy (XPS) depth profile of $\mathrm{Ni}_{2} \mathrm{Al}_{3}$, showing $\mathrm{Al} 2 \mathrm{p}, \mathrm{Ni} 2 \mathrm{p}$, and Ni2p satellite (sat.) peaks.

$\mathrm{Al} 2 \mathrm{p}$ peak is observable at $72.6 \mathrm{eV}, 74.6 \mathrm{eV}$ and $75.6 \mathrm{eV}$ for metallic $\mathrm{Al}, \mathrm{Al}_{2} \mathrm{O}_{3}$ and $\mathrm{AlOx}$-on- $\mathrm{Al}$ respectively. On the surface ( $0 \mathrm{~s}$ sputter time), a main $\mathrm{Al}_{2} \mathrm{O}_{3}$ peak with a side metallic $\mathrm{Al}$ peak can be discerned. Just below the surface (100 s sputter time), the $\mathrm{Al}_{2} \mathrm{O}_{3}$ peak shifts to higher binding energy, corresponding to $\mathrm{Al}$ suboxide-on- $\mathrm{Al}$, while the metallic $\mathrm{Al}$ peak becomes more dominant. In the bulk (up to $1300 \mathrm{~s}$ sputter time), the main peak is metallic $\mathrm{Al}$ with a small sidelobe at higher binding energy, indicating the presence of some $\mathrm{Al}$ suboxide.

TEM-EDS image of $\mathrm{Ni}_{2} \mathrm{Al}_{3}$, illustrated in Figure 9, confirms that the native oxide is composed out of $\mathrm{Al}$ and $\mathrm{O}$. $\mathrm{Ni}$ is confined within the bulk, which also contains $\mathrm{Al}$ and traces of $\mathrm{O}$. The bulk composition therefore has changed compared to nominal. All elements within the bulk metal layer seem to be uniformly distributed. TEM-EDS line scan reveals preferential Al diffusion towards high oxygen concentration, such as at the surface and at the $\mathrm{SiO}_{2}$ interface. This leaves a Ni-rich layer just below the native oxide and on top of $\mathrm{SiO}_{2}$. The Al:O ratio is not stoichiometric 2:3 beneath the surface, indicating formation of sub-oxides where less than the maximum number of $\mathrm{Al}-\mathrm{O}$ bonds were formed.

Figure 10 presents the XRR spectra of $\mathrm{Ni}_{2} \mathrm{Al}_{3}$. The measurements for the other samples can be found in the Supplementary Materials section Figure S2. A multilayered model was used to account for density gradients, with layer thickness, density and roughness as fitting parameters. The nominal line follows the crystalline density of $\mathrm{Al}_{2} \mathrm{O}_{3}$ and $\mathrm{Ni}_{2} \mathrm{Al}_{3}$ along the layer thickness measured from TEM images. The density of the largest bulk layer is considered the bulk density of the film, and is tabulated in Table 4.

Table 4. Comparison of bulk density and composition as determined by XRR to crystalline density and nominal composition for $\mathrm{Ni}_{3} \mathrm{Al}, \mathrm{NiAl}$, and $\mathrm{Ni}_{2} \mathrm{Al}_{3}$. Crystalline density is calculated from lattice parameters found in literature on Material Springer database [46].

\begin{tabular}{cccc}
\hline Characterization & Sample & XRR & Literature/Nominal \\
\hline & $\mathrm{Ni}_{3} \mathrm{Al}$ & $6.95 \pm 0.05$ & $7.44[47]$ \\
Bulk density $\left(\mathrm{g} / \mathrm{cm}^{3}\right)$ & $\mathrm{NiAl}$ & $6.77 \pm 0.12$ & $5.92[48]$ \\
& $\mathrm{Ni}_{2} \mathrm{Al}_{3}$ & $5.46 \pm 0.04$ & $4.75[49]$ \\
\hline & $\mathrm{Ni}_{3} \mathrm{Al}$ & $76.7 / 23.3$ & $75 / 25$ \\
Bulk composition $\mathrm{Ni} / \mathrm{Al}($ at $\% /$ at $\%)$ & $\mathrm{NiAl}$ & $74.3 / 25.7$ & $50 / 50$ \\
& $\mathrm{Ni}_{2} \mathrm{Al}_{3}$ & $54.8 / 45.2$ & $40 / 60$ \\
\hline
\end{tabular}



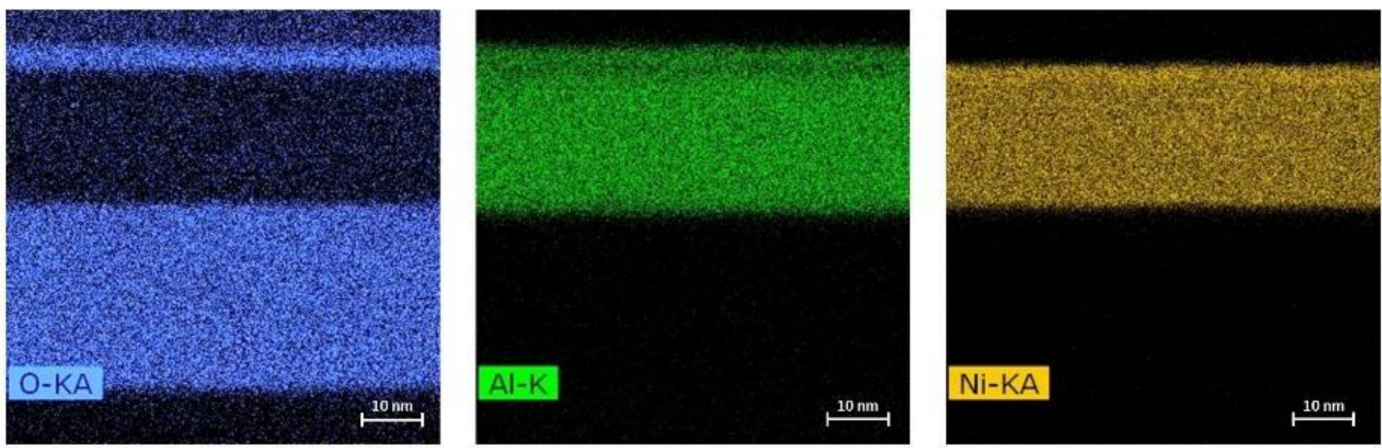

(a)
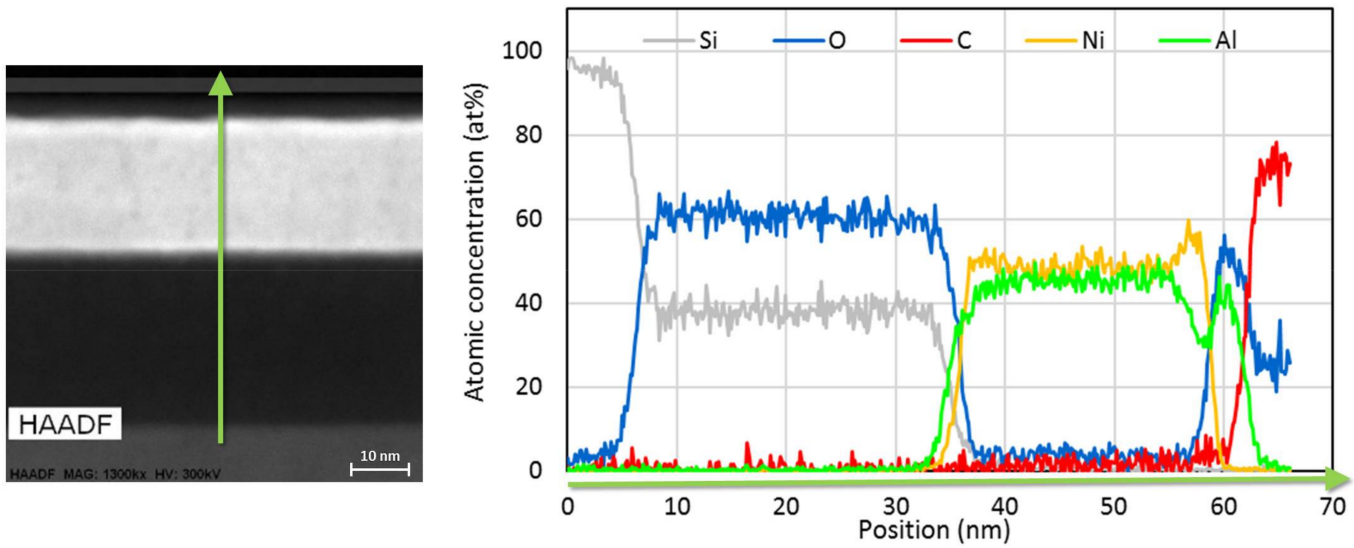

(b)

Figure 9. (a) TEM-EDS images of $\mathrm{Ni}_{2} \mathrm{Al}_{3}$ showing $\mathrm{O}, \mathrm{Al}$, and $\mathrm{Ni}$ traces; (b) TEM-EDS line scan along the arrow direction.

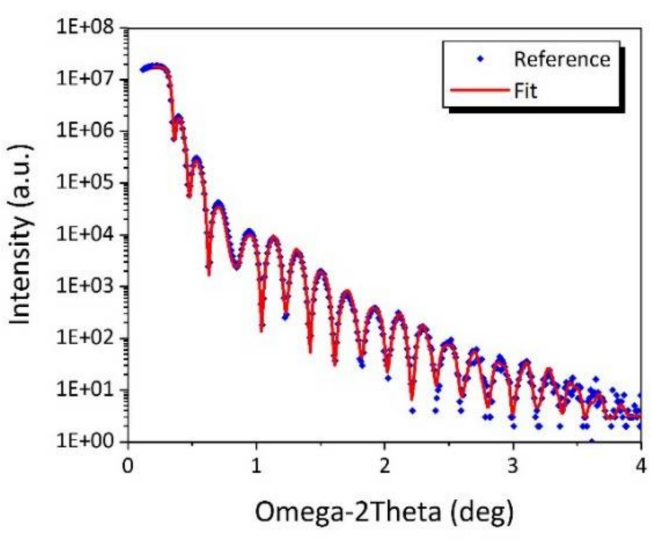

(a)

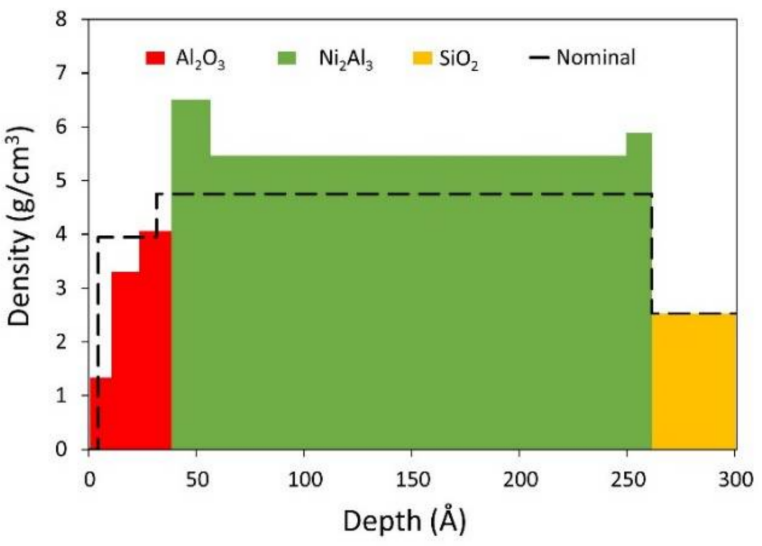

(b)

Figure 10. (a) XRR spectra of $\mathrm{Ni}_{2} \mathrm{Al}_{3}$ showing measured data (blue dots) and fitting result (red line); (b) Density profile of $\mathrm{Ni}_{2} \mathrm{Al}_{3}$ calculated by XRR spectra fit, with the dashed black line representing layer thicknesses based on TEM result and crystalline density based on literature values.

The density calculated with XRR, can differ from crystalline density from literature, due to non-optimized packing order or due to dissimilar bulk composition from nominal, as some $\mathrm{Al}$ diffuses away from bulk to form the native oxide. Two peaks are observable in the $\mathrm{Ni}_{2} \mathrm{Al}_{3}$ density profile: just below the surface oxide and on top of $\mathrm{SiO}_{2}$ substrate, corresponding to the Ni-rich layers where $\mathrm{Al}$ has diffused away. 
The bulk composition can be calculated from bulk density using the rule of mixtures for the mass density of alloy composites, with $w_{i}$ and $\rho_{i}$ the weight percentage in the alloy and density of the $i^{\prime}$ th element respectively:

$$
\rho_{\text {alloy }}=\frac{1}{\sum_{i} \frac{w_{i}}{\rho_{i}}}
$$

Only $\mathrm{Ni}$ and $\mathrm{Al}$ were considered for composition determination without taking into account the $\mathrm{O}$ content. The calculated bulk composition of $\mathrm{Ni}_{3} \mathrm{Al}$ and $\mathrm{NiAl}$ are very similar, around 3:1 Ni:Al ratio. Although the $\mathrm{NiAl}$ sample contains relatively more $\mathrm{Al}$ than $\mathrm{Ni}_{3} \mathrm{Al}$, more $\mathrm{Al}$ has diffused away towards the surface, resulting in a thicker surface oxide layer in the NiAl sample (cf. Figure 4) and a higher $\mathrm{Ni}$ content in the bulk compared to nominal composition. Similarly, the bulk composition of $\mathrm{Ni}_{2} \mathrm{Al}_{3}$ ends up closer to 1:1 Ni:Al ratio.

With the bulk alloy density $\rho_{\text {alloy }}$ and the bulk composition $w_{j}$ from XRR spectra, we can proceed to calculate the optical constants $n, k$ with the Equation (1).

\section{Verification of Optical Constants}

In this section, we compare optical constants, calculated by Equation (1) with values from film characterization in Section 3, and by fitting EUVR measurement. The optical constants will be used in rigorous simulations to predict M3D impact in Section 5.

The first set of $n, \kappa$ is calculated using crystalline density and composition of $\mathrm{Ni}_{\mathrm{x}} \mathrm{Al}_{\mathrm{y}}$ compounds from literature. The second set of optical constants is calculated based on bulk density and bulk composition obtained with XRR. These density and composition values are tabulated in Table 4 . The third set of optical constants are calculated from fitting EUVR data, which were collected with PTB's soft X-ray radiometry beamline at BESSY II facility. The EUV reflectance of $\mathrm{Ni}_{3} \mathrm{Al}, \mathrm{NiAl}$ and $\mathrm{Ni}_{2} \mathrm{Al}_{3}$ was measured through wavelength and through incidence angle. The results have previously been reported in [50]. We fit the measured EUV reflectance with a three-layer stack model, consisting out of native oxide, bulk metal, and $\mathrm{SiO}_{2}$ on Si-substrate. The fitting parameters consist out of layer thickness, and optical constants. The EUV reflectance fits are illustrated in the Supplementary Materials Figure S3; the resulting optical constants at $13.5 \mathrm{~nm}$ wavelength are tabulated Table 5. Figure 11 compares the optical constants obtained through literature, XRR, and EUVR.

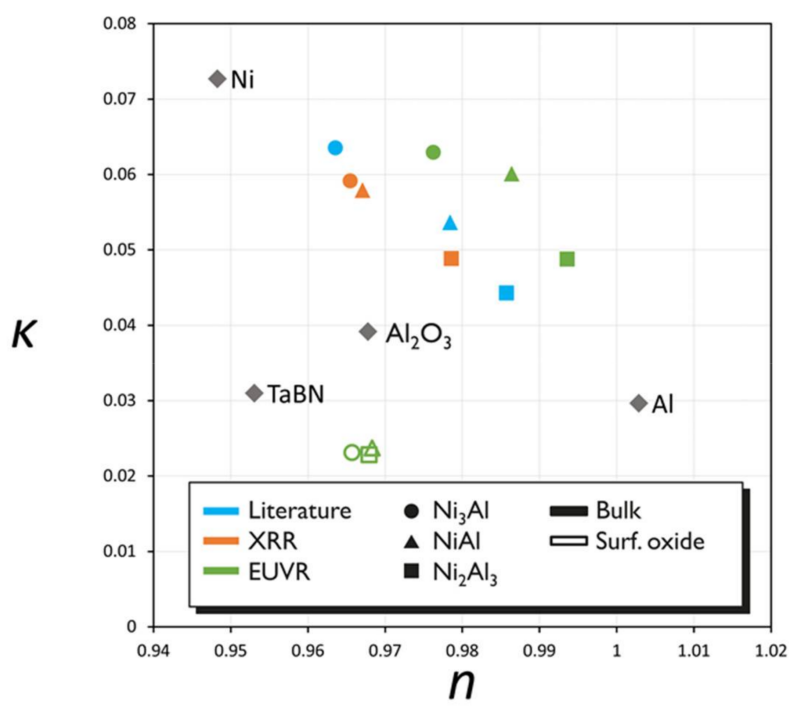

Figure 11. Optical constants of $\mathrm{Ni}_{3} \mathrm{Al}$ (full circle), $\mathrm{NiAl}$ (full triangle), $\mathrm{Ni}_{3} \mathrm{Al}$ (full square), and their surface oxide (open circle, triangle, square): calculated from crystalline density and nominal composition (blue), calculated from XRR measured bulk density and bulk composition (orange), and calculated from EUVR fitting (green). 
Table 5. Optical constants at $13.5 \mathrm{~nm}$ EUV wavelength obtained from fitting EUV reflectometry (EUVR) measurements.

\begin{tabular}{ccccc}
\hline Sample & Bulk $\boldsymbol{n}$ & Bulk $\boldsymbol{\kappa}$ & Oxide $\boldsymbol{n}$ & Oxide $\boldsymbol{\kappa}$ \\
\hline $\mathbf{N i} \mathbf{3} \mathbf{A l}$ & 0.9762 & 0.0630 & 0.9652 & 0.0242 \\
$\mathbf{N i A l}$ & 0.9863 & 0.0601 & 0.9691 & 0.0220 \\
$\mathbf{N i}_{\mathbf{2}} \mathbf{A l}_{\mathbf{3}}$ & 0.9936 & 0.0488 & 0.9681 & 0.0229 \\
\hline
\end{tabular}

EUV reflectance shows higher $\kappa$ with increasing Ni content and $n$ closer to unity with increasing $\mathrm{Al}$ content. The extinction coefficients $\kappa$ are very comparable between calculation based on literature, XRR, and EUVR.

However, EUVR found the refractive coefficients $n$ much closer to unity. The calculated optical constants of the $\mathrm{Ni}_{x} \mathrm{Al}_{\mathrm{y}}$ compounds lie linearly between those from the single elements $\mathrm{Ni}$ and $\mathrm{Al}$, and is based on their tabulated atomic scattering factor $f_{i}$, which is very sensitive to absorption edges. Depending on the chemical state of the element, the absorption edge can shift through wavelength, resulting in different optical constants. Few elements have absorption edges near $13.5 \mathrm{~nm}$ EUV wavelength, one of which is Al. Metallic Al L2 absorption edge lies at $73.1 \mathrm{eV}$ [51], corresponding to a wavelength of $\sim 17 \mathrm{~nm}$, as illustrated in Figure 12a.

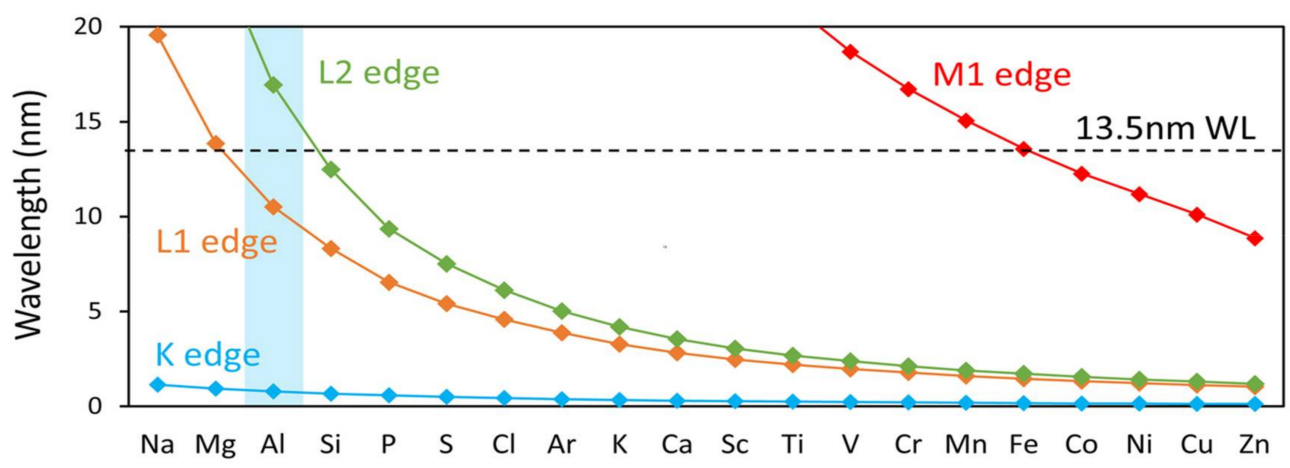

(a)

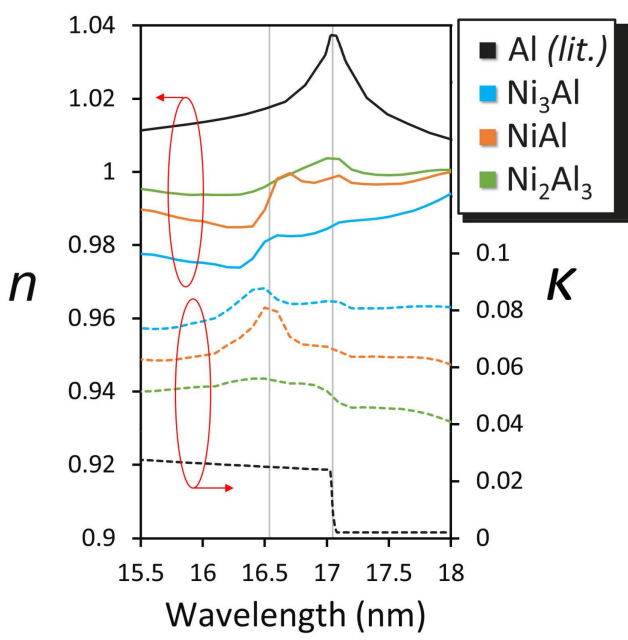

(b)

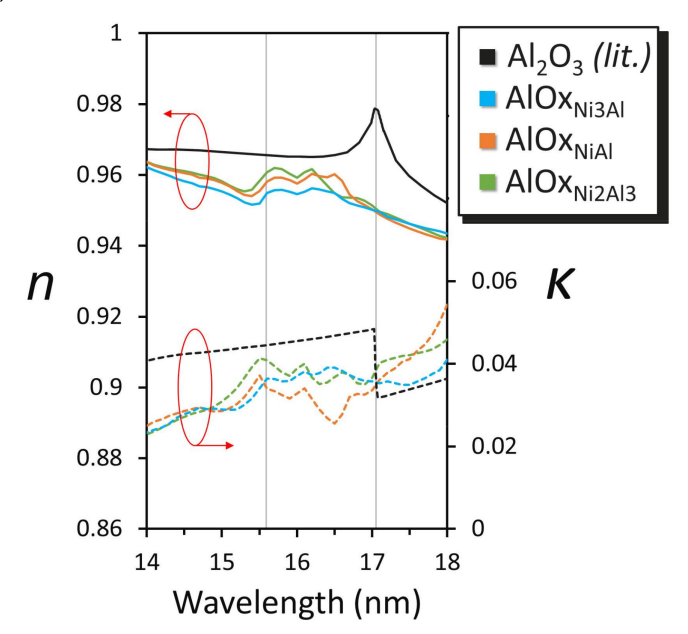

(c)

Figure 12. (a) Absorption edges of elements between $Z=11(\mathrm{Na})$ and $Z=30(\mathrm{Zn})$ through wavelength. Data from Bearden and Burr [51]. Measured Al L2 absorption edge of (b) bulk, and (c) surface oxide of $\mathrm{Ni}_{3} \mathrm{Al}$ (blue), $\mathrm{NiAl}$ (orange), and $\mathrm{Ni}_{2} \mathrm{Al}_{3}$ (green), compared to theoretical $\mathrm{Al} \mathrm{L} 2$ absorption edge of elementary $\mathrm{Al}$ and crystalline $\mathrm{Al}_{2} \mathrm{O}_{3}$ (black) respectively. The refractive coefficient is $n$ represented by full lines, the extinction coefficient $\kappa$ by dashed lines. 
XPS measurements showed partially oxidized $\mathrm{Al}$ at the surface and in the bulk (cf. Figure 8). Higher binding energy of Al-O bonds compared to Al-Al, will shift the Al L2 edge towards higher energy and smaller wavelength. To verify this behavior, additional EUV reflectance was measured between $16 \mathrm{~nm}$ and $18 \mathrm{~nm}$ wavelength to determine the Al L2 absorption edge position. Figure $12 \mathrm{~b}$ reveals a shift of $\mathrm{Al} \mathrm{L} 2$ absorption edge from theoretical position at $17 \mathrm{~nm}$ to $16.6 \mathrm{~nm}$ wavelength. Close to the absorption edge, the refractive coefficient $n$ of $\mathrm{Al}$ varies strongly with the wavelength, therefore the oxidation-induced absorption edge shift significantly impacts the value of $n$ for the $\mathrm{Ni}_{\mathrm{x}} \mathrm{Al}_{\mathrm{y}}$ alloys at $13.5 \mathrm{~nm}$ wavelength. The positive $n$-over-wavelength gradient moves the value of $n$ closer to unity after shifting the absorption edge.

The fitted optical constants of the $\mathrm{Al}_{2} \mathrm{O}_{3}$ native oxide are similar across the $\mathrm{Ni}_{\mathrm{x}} \mathrm{Al}_{\mathrm{y}}$ samples, suggesting there is almost no variation in native oxide composition and density. From Figure 12c, we can observe the $\mathrm{Al} \mathrm{L} 2$ absorption peak has shifted further towards $15.5 \mathrm{~nm}$, as there are more $\mathrm{Al}-\mathrm{O}$ bonds in the surface oxide compared to bulk. Figure 11 shows a much smaller $\kappa$ for the native surface oxide as measured by EUVR, compared to literature values for crystalline $\mathrm{Al}_{2} \mathrm{O}_{3}$. The $\kappa$ reduction is caused by a partial oxidation of the surface layer, resulting in a lower $\mathrm{Al}_{2} \mathrm{O}_{3}$ density as compared to crystalline $\mathrm{Al}_{2} \mathrm{O}_{3}$. The partial oxidation is corroborated by XPS, and TEM; the reduced density by XRR measurements (cf. Figures 8-10). A lower density would also result in larger $n$, yet its value is comparable between EUVR measurement and literature. This can be explained by a combination of the $\mathrm{Al} \mathrm{L} 2$ absorption edge shift, a slightly negative $n$-over-wavelength gradient of $\mathrm{Al}_{2} \mathrm{O}_{3}$, and atypical orbital-atom interactions.

Up to this point, we have presented experimental characterization results, leading up to the determination of realistic $\mathrm{Ni}_{\mathrm{x}} \mathrm{Al}_{\mathrm{y}}$ optical constants with EUVR. In the next section, the measured optical constants will be incorporated in an absorber mask model to simulate and predict the impact on imaging of the $\mathrm{Ni}_{\mathrm{x}} \mathrm{Al}_{\mathrm{y}}$ alloys.

\section{EUV Imaging Simulations}

In this section, we utilize the optical constants, as measured by EUVR and tabulated in Table 5, to predict M3D impact of $\mathrm{Ni}_{\mathrm{x}} \mathrm{Al}_{\mathrm{y}}$ mask absorbers, compared to current TaBN absorber and high $\kappa$ single metal Ni absorber.

We used Synopsys Sentaurus Lithography software to assess intensity threshold-to-size, shadowing effects, best focus shift through pitch, pattern shift through focus, contrast and process window (PW) variation of dense-to-isolated trenches at a fixed CD of $16 \mathrm{~nm}$, which is a relevant structure for the $7 \mathrm{~nm}$ technology node. The simulated illumination source shapes are DipoleY with $90^{\circ}$ opening angle and Quasar with $45^{\circ}$ opening angle at numerical aperture (NA) of 0.33.

The imaging impact of the $\mathrm{Ni}_{\mathrm{x}} \mathrm{Al}_{\mathrm{y}}$ absorbers is compared to the reference $60 \mathrm{~nm} \mathrm{TaBN}$ absorber, and a $32 \mathrm{~nm}$ high $\kappa \mathrm{Ni}$ absorber [9]. The EUV reflective mirror is a calibrated model of an experimentally validated Mo/Si ML mirror capped with $\mathrm{Ru}$ [52]. The $\mathrm{Ni}_{x} \mathrm{Al}_{\mathrm{y}}$ absorber models contains two layers: a surface oxide layer with fixed $3 \mathrm{~nm}$ thickness and a bulk metal absorber layer. The optimal thickness is selected at an EUV reflectance minimum below $2 \%$, as depicted in Figure 13. The optical constants are tabulated in Table 5.

The exposure dose needed to print the patterns on target, is estimated by the intensity threshold-to-size, with high threshold corresponding to low dose. Figure 14a predicts higher threshold-to-size for thin $\mathrm{Ni}_{x} \mathrm{Al}_{\mathrm{y}}$ absorbers, and for high Al-content absorbers. As expected, thinner absorbers and $\mathrm{Al}$ low $\kappa$ result in less EUV dose required to print trenches on target.

Impact on shadowing effect under the Quasar illumination is depicted in Figure $14 \mathrm{~b}$ as the mask $\mathrm{CD}$ difference between horizontal $(\mathrm{H})$ versus vertical $(\mathrm{V})$ patterns, which are biased to print on target at wafer level. All $\mathrm{Ni}_{\mathrm{x}} \mathrm{Al}_{\mathrm{y}}$ absorbers have smaller $\mathrm{HV}$ mask bias compared to reference TaBN and to the thin high $\kappa \mathrm{Ni}$ absorber, despite being physically thicker. Higher $\mathrm{Al}$ content further reduces $\mathrm{HV}$ mask bias. This signifies that shadowing effect is not purely a thickness-induced M3D effect, but is also impacted by phase deformation. 


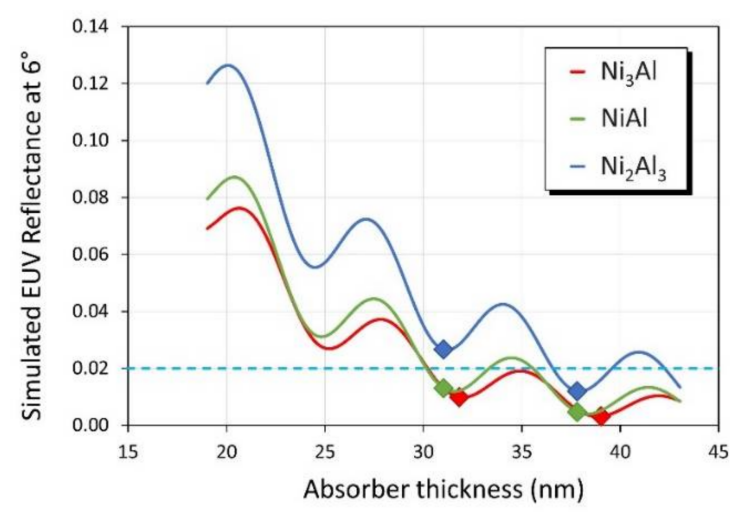

Figure 13. Simulated EUV reflectance at $6^{\circ}$ chief-ray incidence angle over a range of absorber thickness, for $\mathrm{Ni}_{3} \mathrm{Al}, \mathrm{NiAl}$, and $\mathrm{Ni}_{2} \mathrm{Al}_{3}$ absorbers. The dashed line represents the $2 \% \mathrm{EUV}$ reflectance spec. The marks show the absorber thicknesses chosen for the different absorber models.

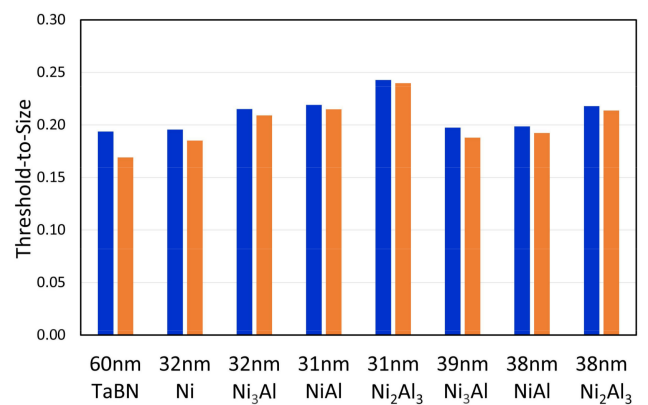

(a)

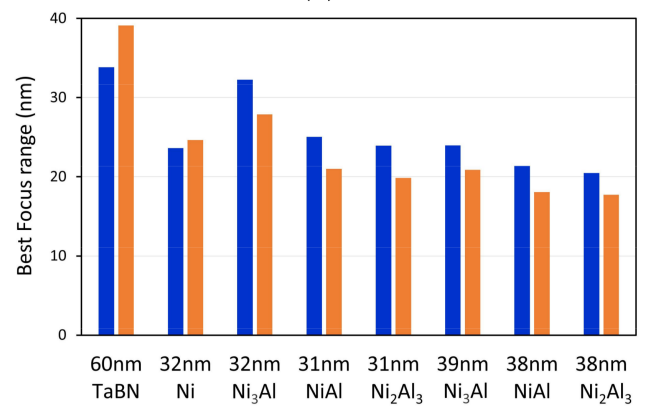

(c)

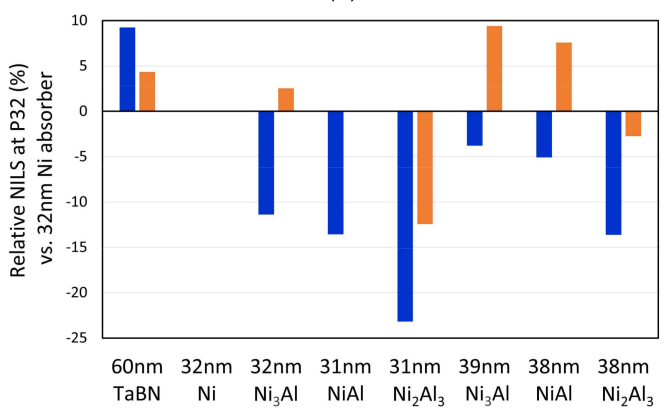

(e)

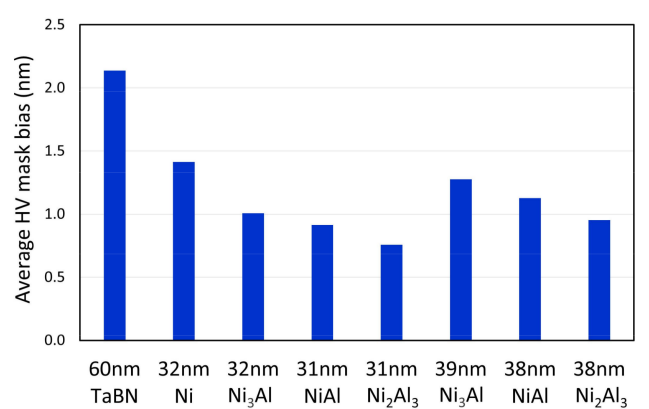

(b)

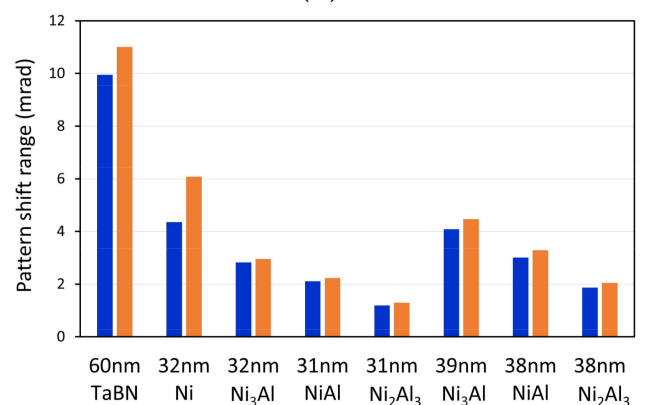

(d)

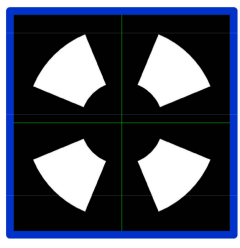

Quasar 45

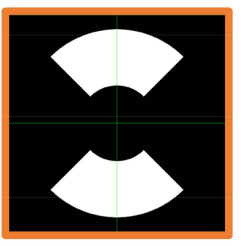

DipoleY 90 (f)

Figure 14. Comparison of (a) threshold-to-size, (b) shadowing effect, (c) best focus shift through pitch, (d) pattern shift through focus, and (e) contrast change normalized to $32 \mathrm{~nm} \mathrm{Ni}$ absorber at $32 \mathrm{~nm}$ pitch for the following absorber stack: $60 \mathrm{~nm}$ TaBN, $32 \mathrm{~nm} \mathrm{Ni}, 32 \mathrm{~nm} \mathrm{Ni} 3 \mathrm{Al}, 31 \mathrm{~nm} \mathrm{NiAl}, 31 \mathrm{~nm}$ $\mathrm{Ni}_{2} \mathrm{Al}_{3}, 39 \mathrm{~nm} \mathrm{Ni} 3 \mathrm{Al}, 38 \mathrm{~nm} \mathrm{NiAl}$, and $38 \mathrm{~nm} \mathrm{Ni}_{2} \mathrm{Al}_{3}$, at $0.33 \mathrm{NA}$ for (f) Quasar (blue) and DipoleY (orange) illumination. 
The best focus range from $32 \mathrm{~nm}$ to $100 \mathrm{~nm}$ trench pitch is shown in Figure 14c. The smaller best focus shift between different pitches is better for overlay. Most $\mathrm{Ni}_{\mathrm{x}} \mathrm{Al}_{\mathrm{y}}$ absorbers exhibit slight reduction in best focus range compared to thin high $\kappa \mathrm{Ni}$ absorber, with more reduction at higher Al-content. More $\mathrm{Al}$ leads to smaller phase deformation as the refractive coefficient $n$ is closer to unity. The thicker $\mathrm{Ni}_{\mathrm{x}} \mathrm{Al}_{\mathrm{y}}$ absorbers have smaller best focus range, as the impact of phase deformation on best focus shift is reduced for darker absorbers with lower reflectance [2].

Figure 14d illustrates the range of pattern shifts through focus for pitches from $32 \mathrm{~nm}$ to $100 \mathrm{~nm}$, expressed in milliradians (mrad). $10 \mathrm{mrad}$ correspond to $1 \mathrm{~nm}$ pattern shift per $100 \mathrm{~nm}$ defocus. Thinner absorbers are preferable as they reduce the contribution of absorber shadowing to pattern shift through focus, as it causes an imbalance in the diffraction orders intensity [5]. Furthermore, with $n$ is close to unity due to $\mathrm{Al}$, there is less phase imbalance between illumination poles under off-axis illumination [6]. Imaging simulations predict all modeled $\mathrm{Ni}_{\mathrm{x}} \mathrm{Al}_{\mathrm{y}}$ absorbers to surpass $\mathrm{TaBN}$ and $\mathrm{Ni}$ in mitigating pattern shift through focus.

The contrast is expressed in normalized intensity log-slope (NILS), with better contrast with higher NILS. In Figure 14e NILS of the Ni absorber at $32 \mathrm{~nm}$ pitch is chosen as reference for each illumination. For the Quasar illumination, TaBN absorber exhibits the best NILS, outperforming all $\mathrm{Ni}_{\mathrm{x}} \mathrm{Al}_{\mathrm{y}}$ absorbers. However, with the DipoleY illumination, which is superior for small patterns, $39 \mathrm{~nm}$ $\mathrm{Ni}_{3} \mathrm{Al}$ and $38 \mathrm{~nm} \mathrm{NiAl}$ absorbers exceed both TaBN and Ni absorbers in NILS.

Lastly, the overlapping process windows under the DipoleY illumination at $0.33 \mathrm{NA}$ are compared between $60 \mathrm{~nm} \mathrm{TaBN}, 32 \mathrm{~nm} \mathrm{Ni}, 39 \mathrm{~nm} \mathrm{Ni}_{3} \mathrm{Al}$-as the $\mathrm{Ni}_{x} \mathrm{Al}_{\mathrm{y}}$ stack with best NILS, and $31 \mathrm{~nm}$ $\mathrm{Ni}_{2} \mathrm{Al}_{3}$-as the $\mathrm{Ni}_{\mathrm{x}} \mathrm{Al}_{\mathrm{y}}$ stack with best M3D reduction. These process windows are determined as the range of exposure dose and focus in which a $16 \mathrm{~nm}$ trench line/space pattern varies $\pm 10 \%$ from target $\mathrm{CD}$. Mask bias has been applied for each pitch, as to print the trenches on target $\mathrm{CD}$ at the specified exposure. The overlap of process windows (oPW) for pitch $32 \mathrm{~nm}, 44 \mathrm{~nm}$ and $60 \mathrm{~nm}$, are shown in Figure 15.

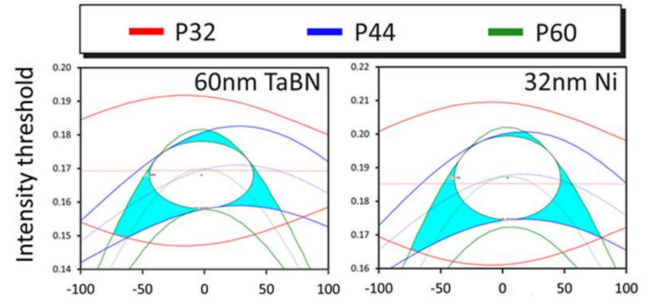

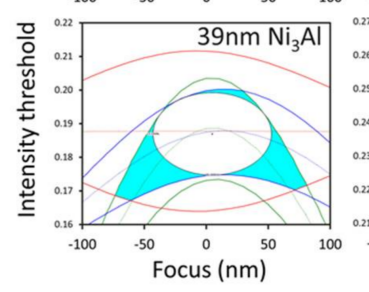

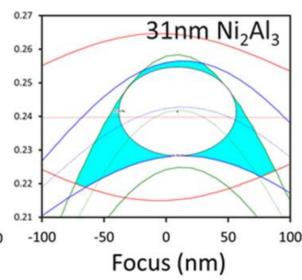

(a)

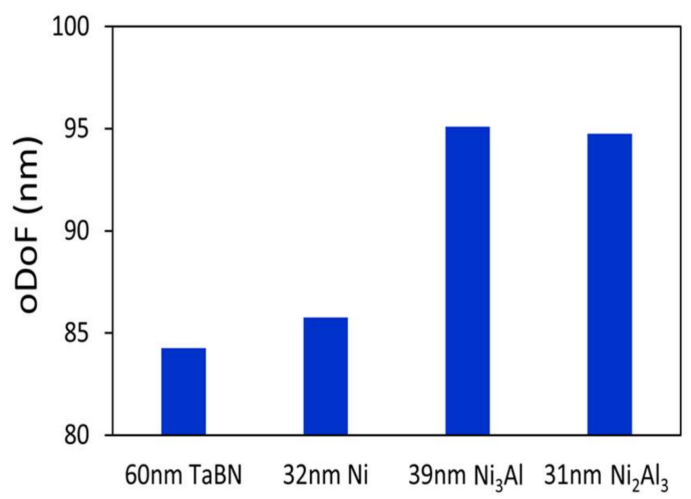

(b)

Figure 15. (a) Overlapping process windows, and (b) overlapping depth-of-focus under the DipoleY illumination at $0.33 \mathrm{NA}$ of $16 \mathrm{~nm}$ trenches at a pitch of $32 \mathrm{~nm}$ (red), $44 \mathrm{~nm}$ (blue), and $60 \mathrm{~nm}$ (green), for $60 \mathrm{~nm} \mathrm{TaBN}, 32 \mathrm{~nm} \mathrm{Ni}, 39 \mathrm{~nm} \mathrm{Ni}_{3} \mathrm{Al}$, and $31 \mathrm{~nm} \mathrm{Ni}_{2} \mathrm{Al}_{3}$ mask absorbers.

The oPW of $\mathrm{Ni}, \mathrm{Ni}_{3} \mathrm{Al}$, and $\mathrm{Ni}_{2} \mathrm{Al}_{3}$ are larger comparing to TaBN. The smallest best focus shift is recognized as the most symmetric oPW, which is the case for the $\mathrm{Ni}_{2} \mathrm{Al}_{3}$ absorber. The overlapping depth-of-focus (oDoF) has increased more than 10\% for the Al containing absorbers, compared to the $\mathrm{TaBN}$ and the $\mathrm{Ni}$ absorber. $\mathrm{Ni}_{3} \mathrm{Al}$ has a similar oDoF compared to $\mathrm{Ni}_{2} \mathrm{Al}$, but is more preferred for its higher NILS. 
In conclusion, based on rigorous EUV imaging simulations, there is a trade-off between phase distortion reduction, and NILS. High Al-content alloys are expected to exhibit significant contrast loss, despite superior phase distortion reduction, especially at reduced absorber thickness. A $39 \mathrm{~nm} \mathrm{Ni} 3 \mathrm{Al}$ turns out to be the best candidate out of the simulated absorber models, with superior M3D mitigation combined with high NILS under DipoleY illumination, when compared to $60 \mathrm{~nm}$ TaBN and $32 \mathrm{~nm}$ Ni absorbers.

\section{Discussion and Outlook}

In this paper, we present an extensive experimental methodology flow to evaluate candidate absorber materials capable of reducing M3D effects. We have started characterizing alloys to a list of specifications, including film morphology, durability under cleaning conditions, and under hydrogen conditions. The optical specification for absorber materials for BIM require high extinction coefficient $\kappa$ and refractive coefficient $n$ close to unity. Before determining the optical constants, the film profile needs to be characterized first with sufficient depth resolution, especially in the case when more than a single layer is formed after deposition. Accurate measurement of the film profile is used to set up an absorber model with improved fitting convergence of the EUV reflectance data, and from which realistic optical constants can be precisely extracted.

Three nominal compositions of the $\mathrm{Ni}-\mathrm{Al}$ system have been investigated with various material and optical characterization techniques.

Alloying $\mathrm{Ni}$ and $\mathrm{Al}$ was unable to remove crystallinity completely, but the $\mathrm{Ni}-\mathrm{Al}$ crystal grain size has decreased compared to pure $\mathrm{Ni}$ crystal grains. The as-deposited $\mathrm{Ni}_{2} \mathrm{Al}_{3}$ alloy shows nano-crystallinity morphology, but recrystallizes above $200{ }^{\circ} \mathrm{C}$. As-deposited $\mathrm{NiAl}$ and $\mathrm{Ni}_{3} \mathrm{Al}$ exhibit poly-crystallinity and retain this morphology at higher temperatures.

A native $\mathrm{Al}_{2} \mathrm{O}_{3}$ layer forms naturally on the $\mathrm{Ni}_{x} \mathrm{Al}_{\mathrm{y}}$ alloy surface when $\mathrm{Al}$ is exposed to atmospheric oxygen. The surface oxide grows with increasing Al-content. A chemical stable capping layer can possibly protect $\mathrm{Al}$ from oxidizing. Alternatively, saturating all $\mathrm{Al}-\mathrm{O}$ bonds resulting in a uniform $\mathrm{Al}_{2} \mathrm{O}_{3}$ composition, can ensure the absorber composition does not change over time.

EUVR verified higher $\kappa$ with increased $\mathrm{Ni}$ content and $n$ closer to unity with increased $\mathrm{Al}$ content. Measurement through wavelength detected A1 L2 absorption edge shift towards $16.6 \mathrm{~nm}$ wavelength, resulting from $\mathrm{Al}$ oxidation in the $\mathrm{Ni}_{\mathrm{x}} \mathrm{Al}_{\mathrm{y}}$ material. This near-edge anomalous scattering behavior causes the refractive coefficient $n$ to be much closer to unity at $13.5 \mathrm{~nm}$ wavelength, which can be advantageous for BIM absorbers.

Lithography imaging simulations predict a trade-off between better phase distortion reduction for high Al-content alloys, and higher contrast for high Ni-content alloys. Nevertheless, higher EUV absorption compared to $60 \mathrm{~nm} \mathrm{TaBN}$, allows the $\mathrm{Ni}_{\mathrm{x}} \mathrm{Al}_{\mathrm{y}}$ absorbers to be thinner, resulting in lower dose-to-size, less shadowing effect, less pattern shift through focus, smaller best focus shift range, and larger overlapping process windows. Taking contrast loss into consideration, the best candidate out of the simulated absorber models is a $39 \mathrm{~nm} \mathrm{Ni}_{3} \mathrm{Al}$ absorber stack.

Although $\mathrm{Ni}$ etch is still challenging, promising mitigation strategies to overcome the issues of $\mathrm{Ni}$ in respect to etch and repair are under investigation. We have demonstrated that $\mathrm{Ni}-\mathrm{Al}$ alloys are worthwhile candidates for mask absorber material with good imaging and mask life time expectations. The presented extensive evaluation of $\mathrm{Ni}-\mathrm{Al}$ alloys is encouraging to increase the efforts in promising patterning strategies for magnetic metals.

Supplementary Materials: The following are available online at http:/ www.mdpi.com/2076-3417/8/4/521/s1: Figure S1. XPS depth profile of of (a) $\mathrm{Ni}_{3} \mathrm{Al}$, and (b) NiAl, showing Ni2p, and Al2p peaks. Figure S2. (left) XRR spectra showing measured data (blue) versus fit(red), and (right) density profile calculated by XRR spectra fit for (a) $\mathrm{Ni}_{3} \mathrm{Al}$, and (b) NiAl. The dashed black line represents the layer thickness based on TEM and crystalline density based on literature values. Figure S3. Comparison of EUVR measurement (colored) versus fit (dashed) for $\mathrm{Ni}_{3} \mathrm{Al}, \mathrm{NiAl}$, and $\mathrm{Ni}_{2} \mathrm{Al}_{3}$ mask absorbers at $10 \mathrm{~nm}, 13.5 \mathrm{~nm}$, and $16 \mathrm{~nm}$ wavelength.

Acknowledgments: This project has received funding from the Electronic Component Systems for European Leadership Undertaking under grant agreement number 662338. This Joint Undertaking receives support from the 
European Union's Horizon 2020 research and innovation program and Netherlands, France, Belgium, Germany, Czech Republic, Austria, Hungary, and Israel. The authors are grateful to C. Adelmann and S. Mertens (IMEC) for their thin film expertise. For metrology support, we thank J. Meersschaut, T. Conard, H. Bender, I. Pollentier, and A. Pacco (IMEC). We appreciate the support of K. Ronse, and S. Van Elshocht (IMEC).

Author Contributions: We confirm that all authors contributed to this study. Eric Hendrickx and Marc Heyns did project management and gave initial ideas. Vu Luong and Vicky Philipsen conceived and designed the experiments. Vu Luong and Karl Opsomer prepared the samples. Vu Luong performed beaker tests, the XRR measurement and analysis. Vu Luong requested RBS, ERDA, XPS, and TEM measurements from imec's metrology support, and analyzed those data. Karl Opsomer and Christophe Detavernier were responsible for XRD and IS-XRD. Christian Laubis and Frank Scholze did the EUVR measurements and analysis. Vicky Philipsen carried out the imaging simulations and analysis. Vu Luong wrote the manuscript. All authors did the final manuscript review.

Conflicts of Interest: The authors declare no conflict of interest.

\section{References}

1. Hill, S.; Ermanoski, I.; Tarrio, C.; Lucatorto, T.; Madey, T.; Bajt, S.; Fang, M.; Chandhok, M. Critical parameters influencing the EUV-induced damage of Ru-capped multilayer mirrors. In Proceedings of the SPIE 6517, Emerging Lithographic Technologies XI, San Jose, CA, USA, 27 February-1 March 2007.

2. Erdmann, A.; Xu, D.; Evanschitzky, P.; Philipsen, V.; Luong, V.; Hendrickx, E. Characterization and mitigation of 3D mask effects in extreme ultraviolet lithography. Adv. Opt. Technol. 2017, 3-4, 187-201. [CrossRef]

3. Davydova, N.; de Kruif, R.; Rolff, H.; Connolly, B.; van Setten, E.; Lammers, A.; Oorschot, D.; Fukugami, N.; Kodera, Y. Experimental approach to EUV imaging enhancement by mask absorber height optimization. In Proceedings of the SPIE 8886, 29th European Mask and Lithography Conference, Dresden, Germany, 25-27 June 2013.

4. Burkhardt, M.; Raghunathan, A. Best focus shift mechanism for thick masks. In Proceedings of the SPIE 9422, Extreme Ultraviolet (EUV) Lithography VI, San Jose, CA, USA, 23-26 February 2015.

5. Philipsen, V.; Hendrickx, E.; Verduijn, E.; Raghunathan, S.; Wood, O.R., II; Soltwisch, V.; Scholze, F.; Davydova, N.; Mangat, P. Imaging impact of multilayer tuning in EUV masks, experimental validation. In Proceedings of the SPIE 9235, Photomask Technology, Monterey, CA, USA, 16-18 September 2014.

6. Shih, C.; Yu, S.; Lu, Y.; Chung, C.; Chen, J.; Yen, A. Mitigation of image contrast loss due to mask-side non-telecentricity in an EUV scanner. In Proceedings of the SPIE 9422, Extreme Ultraviolet (EUV) Lithography VI, San Jose, CA, USA, 23-26 February 2015.

7. Finders, J.; Galvier, J. Mask 3D induced phase and the mitigation by absorber optimization. In Proceedings of the SPIE 9426, Optical Microlithography XXVIII, San Jose, CA, USA, 24-26 February 2015.

8. Wood, O.R., II; Raghunathan, S.; Mangat, P.; Philipsen, V.; Luong, V.; Kearney, P.; Verduijn, E.; Kumar, A.; Patil, S.; Laubis, C.; et al. Alternative materials for high numerical aperture extreme ultraviolet lithography mask stacks. In Proceedings of the SPIE 9422, Extreme Ultraviolet (EUV) Lithography VI, San Jose, CA, USA, 23-26 February 2015.

9. Philipsen, V.; Luong, V.; Souriau, L.; Hendrickx, E.; Erdmann, A.; Xu, D.; Evanschitzky, P.; van de Kruijs, R.W.E.; Edrisi, A.; Scholze, F.; et al. Reducing EUV mask 3D effects by alternative metal absorbers. In Proceedings of the SPIE 10143, Extreme Ultraviolet (EUV) Lithography VIII, San Jose, CA, USA, 27 February-2 March 2017.

10. Van Look, L.; Mochi, I.; Philipsen, V.; Gallagher, E.; Hendrickx, E.; McIntyre, G.; Wittebrood, F.; Lyakhova, K.; de Winter, L.; Last, T.; et al. Mask 3D effect mitigation by source optimization and assist feature placement. In Proceedings of the International Symposium on Extreme Ultraviolet Lithography, Hiroshima, Japan, 24-26 October 2016.

11. Mochi, I.; Philipsen, V.; Gallagher, E.; Hendrickx, E.; Lyakhova, K.; Wittebrood, F.; Schiffelers, G.; Fliervoet, T.; Wang, S.; Hsu, S.; et al. Assist features: Placement, impact, and relevance for EUV imaging. In Proceedings of the SPIE 9776, Extreme Ultraviolet (EUV) Lithography VII, San Jose, CA, USA, 22-25 February 2016.

12. Van Schoot, J.; Schenau, K.V.; Bottiglieri, G.; Troost, K.; Zimmerman, J.; Migura, S.; Kneer, B.; Neumann, J.; Kaiser, W. EUV high-NA scanner and mask optimization for sub $8 \mathrm{~nm}$ resolution. In Proceedings of the SPIE 9635, Photomask Technology, Monterey, CA, USA, 29-30 September 2015. 
13. Philipsen, V.; Luong, V.; Hendrickx, E.; Erdmann, A.; Xu, D.; Evanschitzky, P.; van de Kruijs, R.R.; Edresi, A.; Scholze, F.; Laubis, C.; et al. Mitigating EUV mask 3D effects by alternative metal absorbers. In Proceedings of the EUVL Symposium, Hiroshima, Japan, 24-26 October 2016.

14. Henke, B.; Gullikson, E.; Davis, J. X-ray interactions: Photoabsorption, scattering, transmission, and reflection at $\mathrm{E}=50-30,000 \mathrm{eV}, \mathrm{Z}=1-92$. Atomic Data Nucl. Data Tables 1993, 54, 181-342. [CrossRef]

15. Luong, V.; Philipsen, V.; Scholze, F.; Kruijs, R.V.; Edrisi, A.; Wood, O.R., II; Singh, M.; Hendrickx, E.; Heyns, M. Optimized EUV Mask Absorber Stack for Improved Imaging by Reducing Crystallinity of Alternative Absorber Materials. In Proceedings of the International Symposium on Extreme Ultraviolet Lithography, Hiroshima, Japan, 24-26 October 2016.

16. Constantin, R.; Steinmann, P.; Manasterski, C. Decorative PVD coatings. In Nanomaterials and Surface Engineering; ISTE Ltd.: London, UK; John Wiley \& Sons, Inc.: Hoboken, NJ, USA, 2010; pp. 153-155.

17. Yan, P.Y. Impact of EUVL mask buffer and absorber material properties on mask quality and performance. In Proceedings of the SPIE 4688, Emerging Lithographic Technologies VI, Santa Clara, CA, USA, 5-7 March 2002.

18. Erdmann, A.; Evanschitzky, P.; Neumann, J.T.; Graeupner, P. Mask-induced best-focus shifts in deep ultraviolet and extreme ultraviolet lithography. J. Micro/Nanolithogr. MEMS MOEMS 2016, 15, 021205. [CrossRef]

19. Saltykov, P.; Cornish, L.; Cacciamani, G.; MSIT ${ }^{\circledR}$; Effenberg, G. (Eds.) Al-Ni Binary Phase Diagram Evaluation. Phase Diagrams, Crystallographic and Thermodynamic Data: Datasheet from MSI Eureka in SpringerMaterials. MSI Materials Science International Services GmbH, SpringerMaterials. 2004. Available online: http:/ / materials.springer.com/msi/docs/sm_msi_r_20_010238_01 (accessed on 14 December 2017).

20. Tamura, S.; Kanayama, K.; Nishiyama, Y.; Matsuo, T.; Tamura, A. Optimization of TaSix absorber stack. In Proceedings of the SPIE 6283, Photomask and Next-Generation Lithography Mask Technology XIII, Yokohama, Japan, 18-20 April 2006.

21. Hayashi, K.; Uno, T. Reflective Mask Blank for Euv Lithography. U.S. Patent 13/346,026, 3 May 2012.

22. Mirkarimi, P.B.; Montcalm, C. Advances in the reduction and compensation of film stress in high-reflectance multilayer coatings for extreme-ultraviolet lithography. In Proceedings of the 23rd Annual International Symposium on Microlithography, Santa Clara, CA, USA, 22-27 February 1998.

23. Gallagher, E.E.; Vanpaemel, J.; Pollentier, I.; Zahedmanesh, H.; Adelmann, C.; Huyghebaert, C.; Jonckheere, R.; Lee, J.U. Properties and performance of EUVL pellicle membranes. In Proceedings of the SPIE 9635, Photomask Technology, Monterey, CA, USA, 29-30 September 2015.

24. Pollentier, I.; Vanpaemel, J.; Lee, J.U.; Adelmann, C.; Zahedmanesh, H.; Huyghebaert, C.; Gallagher, E.E. EUV lithography imaging using novel pellicle membranes. In Proceedings of the SPIE 9776, Extreme Ultraviolet (EUV) Lithography VII, San Jose, CA, USA, 22-25 February 2016.

25. Dattilo, D.; Dietze, U.; Hsu, J.-W. Ruthenium capping layer preservation for $100 \mathrm{X}$ clean through $\mathrm{pH}$. In Proceedings of the SPIE 9635, Photomask Technology, Monterey, CA, USA, 29-30 September 2015.

26. Hosoya, M.; Sakaya, N.; Nozawa, O.; Shiota, Y.; Hamamoto, K.; Nagarekawa, O.; Shimojima, S.; Shoki, T.; Watanabe, T.; Kinoshita, H. Evaluating the Optical Index of Ta and Ta-Based Absorbers for an Extreme Ultraviolet Mask Using Extreme Ultraviolet Reflectometry. Jpn. J. Appl. Phys. 2008, 47, 4898-4905. [CrossRef]

27. Qi, Z.J.; Gallagher, E.; Negishi, Y.; McIntyre, G.; Zweber, A.; Senna, T.; Akutagawa, S.; Konishi, T. Impact of EUV photomask line-edge roughness on wafer prints. In Proceedings of the SPIE 8522, Photomask Technology, Monterey, CA, USA, 11-13 September 2012.

28. Qi, Z.J.; Rankin, J.; Sun, L.; Levinson, H. Contribution of EUV mask CD variability on LCDU. In Proceedings of the SPIE 10143, Extreme Ultraviolet (EUV) Lithography VIII, San Jose, CA, USA, 27 February-2 March 2017.

29. Chiba, A.; Takahashi, M.; Yamanashi, H.; Hoko, H.; Hoshino, E.; Hirano, N.; Lee, B.T.; Ogawa, T.; Ito, M.; Okazaki, S. Theoretical Analysis of Placement Error due to Absorber Pattern on Extreme Ultraviolet Lithography Mask. Jpn. J. Appl. Phys. 2002, 40, 5342. [CrossRef]

30. Patil, S.; Singh, S.; Okoroanyanwu, U.; Wood, O.; Mangat, P. Mask Structures and Methods of Manufacturing. U.S. Patent 9195132 B2, 30 January 2014.

31. Soufli, R.; Bajt, S. Multilayer Coatings for EUVL. In EUV Lithography; Bakshi, V., Ed.; John Wiley \& Sons: Hoboken, NJ, USA, 2009; p. 189. 
32. Smith, K.H.; Wasson, J.; Mangat, P.; Dauksher, W.; Resnick, D. Cr absorber etch process for extreme ultraviolet lithography mask fabrication. J. Vac. Sci. Technol. B 2001, 19, 2906. [CrossRef]

33. Du, Y.; Choi, C.; Zhang, G.; Park, S.; Yan, P.; Baik, K. TaN-based EUV mask absorber etch study. In Proceedings of the SPIE 6283, Photomask and Next-Generation Lithography Mask Technology XIII, Yokohama, Japan, 18-20 April 2006.

34. Demirci, E.; Winkler, A. Condensation and desorption of nickel tetra-carbonyl on Cu (1 110$)$. Surf. Sci. 2009, 603, 3068-3071. [CrossRef]

35. Chen, J.; Altieri, N.; Kim, T.; Chen, E.; Lill, T.; Shen, M.; Chang, J. Directional etch of magnetic and noble metals. II. Organic chemical vapor etch. J. Vac. Sci. Technol. 2017, 35, 05C305. [CrossRef]

36. Kanarika, K.J.; Tan, S.; Yang, W.; Kim, T.; Lill, T.; Kabansky, A.; Hudson, E.A.; Ohba, T.; Nojiri, K.; Yu, J.; et al. Predicting synergy in atomic layer etching. J. Vac. Sci. Technol. A Vac. Surf. Films 2017, 35, 05C302. [CrossRef]

37. Philipsen, V.; Luong, V.; Souriau, L.; Altamirano-Sánchez, E.; Adelmann, C.; Laubis, C.; Scholtze, F.; Kruemberg, J.; Reuter, C.; Hendrickx, E. Single element and metal alloy novel EUV mask absorbers for improved imaging. In Proceedings of the SPIE 10450, International Conference on Extreme Ultraviolet Lithography, Monterey, CA, USA, 11-14 September 2017.

38. Bajt, S. Optics Contamination. In EUV Lithography; Bakshi, V., Ed.; John Wiley \& Sons: Hoboken, NJ, USA, 2009; pp. 229-230.

39. Youssef, M.; Yang, M.; Yildiz, B. Doping in the Valley of Hydrogen Solubility: A Route to Designing. Phys. Rev. Appl. 2016, 5, 014008. [CrossRef]

40. Cho, H.; Ahn, J. EUV Mask and Mask Metrology. In EUV Lithography; Bakshi, V., Ed.; John Wiley \& Sons: Hoboken, NJ, USA, 2009; p. 351.

41. Waiblinger, M.; Kornilov, K.; Hofmann, T.; Edinger, K. e-beam induced EUV photomask repair-A perfect match. In Proceedings of the European Mask and Lithography Conference, Grenoble, France, 18-20 January 2010.

42. Lawliss, M.; Gallagher, E.; Hibbs, M.; Seki, K.; Isogawa, T.; Robinson, T.; LeClaire, J. Repairing native defects on EUV mask blanks. In Proceedings of the SPIE 9235, Photomask Technology, Monterey, CA, USA, 16-18 September 2014.

43. Muniz, F.T.L.; Miranda, M.A.R.; Santosa, C.M.d.; Sasaki, J.M. The Scherrer equation and the dynamical theory of X-ray diffraction. Acta Crystallogr. Sect. A Found. Adv. 2016, 72, 385-390. [CrossRef] [PubMed]

44. Pourbaix, M. Atlas of Electrochemical Equilibria in Aqueous Solutions; National Association of Corrosion Engineers: Houston, TX, USA, 1974; Volume 52, p. 171.

45. Rastegar, A.; House, M.; Tian, R.; Laursen, T.; Antohe, A.; Kearney, P. Study of alternative capping and absorber layers for extreme ultraviolet (EUV) masks for sub-16nm half-pitch nodes. In Proceedings of the SPIE 9048, Extreme Ultraviolet (EUV) Lithography V, San Jose, CA, USA, 24-27 February 2014.

46. Springer Materials. Springer International Publishing. Available online: http://materials.springer.com/ (accessed on 4 January 2018).

47. Han, K.; Choo, W. Carbon effect on ordering of $\gamma^{\prime}-\mathrm{Ni3Al}$ in rapidly solidified Ni3Al-C alloys. Scr. Metall. 1983, 17, 281-284. [CrossRef]

48. Rusovic, N.; Henig, E. Influence of Supersaturated Thermal Vacancies on the Elastic Constants of $\beta 2-N i A 1$. Phys. Status Solidi A Appl. Res. 1980, 57, 529-540. [CrossRef]

49. Sridharan, S.; Nowotny, H.; Wayne, S. Investigations within the Quaternary System Titanium-Nickel-Aluminium-Carbon. Monatshefte für Chemie 1983, 114, 127-135. [CrossRef]

50. Scholze, F.; Laubis, C.; Luong, K.V.; Philipsen, V. Update on optical material properties for alternative EUV mask absorber materials. In Proceedings of the 33rd European Mask and Lithography Conference, Dresden, Germany, 26-28 June 2017.

51. Bearden, J.; Burr, A. Reevaluation of X-Ray Atomic Energy Levels. Rev. Mod. Phys. 1967, 39, 125-142. [CrossRef]

52. Philipsen, V.; Hendrickx, E.; Jonckheere, R.; Davydova, N.; Fliervoet, T.; Neumann, J.T. Actinic characterization and modeling of the EUV mask stack. In Proceedings of the SPIE 8886, 29th European Mask and Lithography Conference, Dresden, Germany, 25-27 June 2013.

(C) 2018 by the authors. Licensee MDPI, Basel, Switzerland. This article is an open access article distributed under the terms and conditions of the Creative Commons Attribution (CC BY) license (http:/ / creativecommons.org/licenses/by/4.0/). 